\title{
Influence of Structural Parameters of Shape Memory Alloy Corrugated Gaskets on the Contact Pressure of Bolted Flange Joints
}

\author{
Liang He, ${ }^{1}$ Xiaofeng Lu, ${ }^{1}$ Xiaolei Zhu ${ }^{D},{ }^{1}$ and Qing Chen ${ }^{2}$ \\ ${ }^{1}$ College of Mechanical and Power Engineering, Nanjing Tech University, Nanjing 211800, China \\ ${ }^{2}$ College of Mechanical and Electrical Engineering, Jilin Institute of Chemical Technology, Jilin City 132022, China
}

Correspondence should be addressed to Xiaolei Zhu; zhuxiaolei@njtech.edu.cn

Received 23 February 2021; Revised 18 May 2021; Accepted 27 May 2021; Published 7 June 2021

Academic Editor: Jun Liu

Copyright (c) 2021 Liang He et al. This is an open access article distributed under the Creative Commons Attribution License, which permits unrestricted use, distribution, and reproduction in any medium, provided the original work is properly cited.

Shape memory alloy corrugated gaskets (SMA-CGs) can adapt to fluctuating working conditions due to their pseudoelasticity (PE) and shape memory effect (SME), which make them excellent sealing components. In this study, the deformation mechanism of SMA-CGs was examined according to their structural properties under installation and operating conditions to establish an SMA-CG thermal-mechanical coupling model with the finite element analysis (FEA) method, which has been verified through experimentation. Based on this, a thermal-mechanical coupling FEA model was built for a bolted flange joint with SMA-CG. The influence of the SMA-CG structure parameters on compression-rebound mechanical properties was also studied under installation and operating conditions. The conclusions are as follows: a thermal-mechanical coupling finite element analysis method was established for NiTi alloy corrugated structures. Through comparison with the experimental results, the maximum error of the maximum compression load was $5.78 \%$, the maximum error of the rebound rate was $8.85 \%$, and the maximum error of the maximum compaction force in the heat recovery stage was $12.2 \%$, all of which were within the $<15 \%$ acceptable error range of engineering fields. According to the related experiments and finite element results, the maximum compressive force of gasket thermal recovery after unloading was not less than $40 \%$ of the initial maximum compressive load. The application of shape memory alloy to corrugated gasket significantly improved its ability in coping with fluctuating load temperatures. The contact pressure of corrugation increased with the increase of sheet thickness $(T)$ and corrugated gasket height $(H)$ under installation and operating conditions, showing a decreasing trend with the increase of pitch $(P)$, of which the order of factors influencing the average contact pressure of corrugated gasket was sheet $T>H>P$, and when structural parameters of SMA-CG were $T=0.6 \mathrm{~mm}$, $H=4 \mathrm{~mm}$, and $P=2.5 \mathrm{~mm}$, the contact pressure of corrugated gasket was the highest under operating conditions.

\section{Introduction}

As an important detachable connection method for processing industries, bolted flange connections have been widely used in the fields of chemical industry, nuclear energy, aerospace, and so on. As the core component of bolted flange connection for sealing, gasket must adapt to the bolt load loss caused by temperature changes and load fluctuations in the process of flange connection, so as to ensure sealing performance of connection system [1]. Metal corrugated gaskets have good compressive resilience and high linear sealing specific pressure, which have been broadly applied in the fields of chemical industry, nuclear energy, aerospace, and so on [2].

Shape memory alloy (SMA) is a promising sealing material, and its shape memory effect (SME) and pseudoelasticity (PE) can effectively improve the reliability of bolted flange connection sealing under fluctuating load conditions. Therefore, SMA is the preferred gasket material for improving the sealing reliability of connection joints of high-parameterized equipment under fluctuating conditions.

The application of SMAs in flat gaskets has been extensively studied by various scholars. Tatsuoka et al. [3-5] preliminarily evaluated the sealing performance of SMA flat 
gaskets at room and variable temperatures through experimentation and finite element methods, with the results showing that the SMA flat gasket possesses good sealing performance under both installation and operation conditions. The research findings of $\mathrm{Lu}$ et al. [6, 7] further demonstrated that a suitable aging heat treatment method and reasonable operating temperature might be the causes that make SMA flat gaskets exert far better compression resilience than ordinary metal gaskets. The disadvantage of SMA flat gaskets is high material hardness, which can damage flange surfaces and affect the secondary use of joints.

Structural gaskets have advantages including high sealing reliability and good pretightening force designability, which have become the main focus in the development of bolted flange joint gaskets, such as spiral wound gaskets and corrugated gaskets. Early corrugated gaskets were mostly used as sealing components, together with graphite filling. In leakage rate experiments, it was found that carbon steel corrugated gaskets with graphite filling possess better sealing performance than flat gaskets at a larger compression rate [8].

To improve the sealing reliability of gaskets, Saeed et al. [9] proposed a new corrugated gasket referring to the traditional structure of corrugated gasket. After structural optimization, the sealing reliability of the corrugated gasket was significantly improved. Figure 1 shows the new corrugated gasket compared with a traditional one. According to the studies of Choiron et al. [10-12] and Shigeyuki et al. [13], this new corrugated gasket was analyzed, to discuss its structural parameters from different aspects of contact pressure, contact width, and deformation mode, and finally, its structural parameters with higher sealing reliability were obtained. Nurhadiyanto et al. $[14,15]$ introduced a coating layer for the new corrugated gasket, which improved the influence of contact surface roughness on the leakage rate. Efremov [16-19] proposed a concept of SMA corrugated gasket to improve compressive resilience and sealing performance. They combined SME and PE properties of SMA and proposed a method to prepare SMA corrugated gaskets with a "negative creep" effect under operating conditions. Zhan et al. [1] explored the influence of SMA-CG preparation on the mechanical properties of gasket and found that corrugated gasket exhibits the best mechanical properties, with a setting temperature of $500^{\circ} \mathrm{C}$ and a setting time of $1 \mathrm{~h}$. SMA has been proven to be a good sealing material. Combining its SME and PE with corrugated gaskets can effectively reduce the pretightening force of advanced equipment connection joints and improve the reliability of joint sealing under fluctuating conditions. However, the current research on SMA-CGs is only focused on the conceptual design and preparation process of gaskets, and the influencing factors of their mechanical properties have not been systematically studied. Scholars used the thermalmechanical coupling finite element method to study the contact stress distribution of shape memory alloy flat gaskets in a bolted flange connection system under a uniform temperature field, only referring to the general metal gasket modeling method [4]. The finite element method uses the gasket element to simulate the shape memory effect of shape

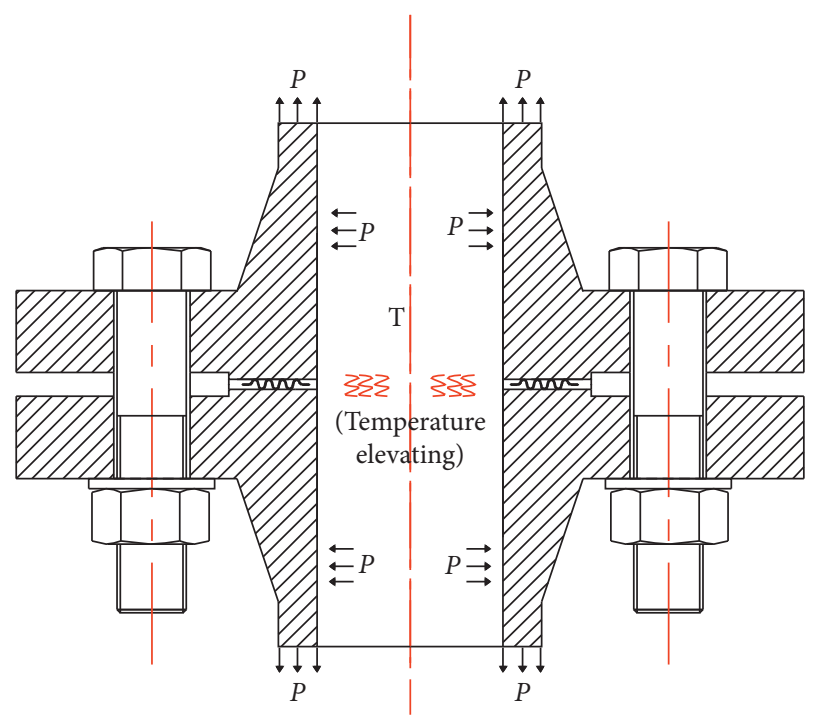

FIGURE 1: Bolted flange connection.

memory alloy gaskets. The SMA-CG is similar to the ordinary corrugated gasket, and the nonlinearity of materials and geometry is involved in the loading process. At the same time, the phase change behavior of SMA-CGs is also nonuniform compared with flat gaskets. In this case, the gasket element is not suitable for the simulation of shape memory alloys.

Therefore, according to the deformation mechanism of sealing gaskets under installation and operating conditions, a constitutive SMA model was established, with an SMA-CG thermal-mechanical coupling FEA method developed in this study combined with the phase transformation mechanism of SMA. Comparing the calculated results with the experimental results, the influence of structure and size of gasket on the changes of deformation mechanism and contact pressure of SMA corrugated gasket was explored with the proposed method. It is hoped that the findings of this study can lay a foundation for further engineering applications of SMA-CGs.

\section{Deformation Mechanism and Constitutive Relationship of SMAs for Gaskets}

A schematic diagram of a bolted flange connection joint is shown in Figure 1. The joint consists of bolts, nuts, an upper flange, a lower flange, and a gasket placed between upper and lower flanges. Under installation conditions, as the nut is tightened, the initial pretightening force applied on the bolt can result in the elastic deformation of gasket. When the load continues, the surface of gasket undergoes partial plastic deformation and fits with the surface of flange until a reliable sealing surface is formed. Under operating conditions, the internal pressure $P$ acts on upper and lower end faces of flanges, resulting in decreased bolt pretightening force and partial rebound of gasket. As the temperature on the joint increases gradually, the gasket, bolts, and flanges all expand. However, due to dissimilarities in the three materials and their thermal expansion coefficients, the gasket deformation 
process is extremely complex, which usually decrease the pretightening force and rebound the gasket. When the recovery rate of gasket is lower than the elongation of bolt, there will be a joint failure caused by leakage results.

Under installation conditions, contact pressure on the surface of SMA gaskets increases with an increase in bolt pretightening force, and Mises stress exceeds the critical initial phase transformation stress $\sigma_{\mathrm{Ms}}$ of detwinned martensite. And then, the SMA gasket can be transformed from twinned martensite to detwinned martensite, which is pseudoelastically deformed. Under operating conditions, as the internal pressure $P$ is applied, the gasket partially rebounds. With the increase of temperature, the internal temperature $T$ will exceed the austenite phase transformation starting temperature $T_{\mathrm{As}}$, which can promote the transformation of detwinned martensite into austenite in SMA gaskets. During this time, the SME of SMA plays an important role, and the gasket is recovered from the deformed state back to its initial shape, which will effectively guarantee the contact pressure of gasket and improve the sealing reliability of the joint. Meanwhile, with gradually increasing in temperature, since the SMA gasket is restricted by the surface of flange within a certain range of temperature, the recovery stress hinders the reverse phase transformation of detwinned martensite, which will not completely transform into austenite [20]. Detwinned martensite has a lower elastic modulus than austenite, prone to deformation, which can effectively fill up the leakage channel on the surface of the flange, forming an initial sealing condition, to ensure the sealing characteristics of the gasket.

On this basis, the SMA gasket undergoes a phase transformation from twinned martensite to detwinned martensite and then to austenite under installation and service conditions. Assuming that the elastic moduli of twinned martensite and austenite are equal, a constitutive SMA gasket model was proposed in this paper based on the research of Ben Jaber [21, 22].

During the deformation of the SMA gasket, its total strain rate is decomposed into elastic strain rate $\dot{\varepsilon}_{\text {el }}$ and phase transformation strain rate $\dot{\varepsilon}_{\text {tr }}$ as follows:

$$
\dot{\varepsilon}=\dot{\varepsilon}_{\text {el }}+\dot{\varepsilon}_{\text {tr }}
$$

According to Jaumann rate of Cauchy stress, the stress increment equation can be expressed as follows:

$$
\dot{\sigma}=R\left(\dot{\varepsilon}-\dot{\varepsilon}_{\text {tr }}\right)+\dot{R}\left(\varepsilon-\varepsilon_{\text {tr }}\right)+k \dot{T}+\dot{k}\left(T-T_{\text {ref }}\right),
$$

where $R$ is the elastic stiffness tensor, $k$ is the thermal modulus vector, $T$ is the real-time temperature, and $T_{\text {ref }}$ is the initial temperature. The transformation strain rate can be determined as follows:

$$
\dot{\varepsilon}_{\mathrm{tr}}= \begin{cases}\dot{\xi}_{\mathrm{tr}}^{\max } \frac{\sigma}{\sqrt{\sigma^{2}+3 \tau^{2}}}, & \text { if } \dot{\xi}>0, \\ \dot{\xi}_{\mathrm{tr}}, & \text { if } \dot{\xi}<0,\end{cases}
$$

where $\varepsilon_{\mathrm{tr}}^{\max }$ is the maximum residual martensite transformation strain under a uniaxial tension condition. For transformation from twinned martensite to detwinned martensite or martensite to austenite, the evolution equation of volume fraction of detwinned martensite can be expressed as follows:

$$
\dot{\xi}=(1-\xi) \frac{\dot{\varepsilon}^{A M}}{\varepsilon_{f}^{A M}-\varepsilon^{A M}} .
$$

Then, the control function $\varepsilon^{A M}(\varepsilon, T)$ defines the strain state as follows:

$$
\varepsilon^{A M}= \begin{cases}C_{A M}^{*}\left(T-T_{0}\right)+\varepsilon_{\mathrm{eq}}, & \text { if } T_{0} \geq T_{S}^{A M}, \\ \varepsilon_{\mathrm{eq}}, & \text { if } T_{0}<T_{S}^{A M},\end{cases}
$$

where $\varepsilon_{f}^{A M}$ is the critical end strain of the transformation of detwinned martensite, $C_{A M}^{*}$ is the influence coefficient of austenite, and $\varepsilon_{\text {eq }}$ is the equivalent strain.

For the transformation from detwinned martensite to austenite, the evolution equation of detwinned martensite can be expressed as follows:

$$
\dot{\xi}=-\xi \frac{\dot{\varepsilon}^{M A}}{\varepsilon_{f}^{M A}-\varepsilon^{M A}} .
$$

The control function $\varepsilon^{M A}(\varepsilon, T)$ defines the strain state as follows:

$$
\varepsilon^{M A}=c_{M A}^{*}\left(T-T_{0}\right)+\varepsilon_{\text {eq }},
$$

where $\varepsilon_{f}^{M A}$ is the critical end strain of detwinned martensite and $C_{M A}^{*}$ is the influence coefficient of austenite phase.

Generally, the plastic yield stress of SMAs is higher than detwinned martensite transformation stress; that is, plastic deformation will only occur when the phase transformation is completed. Due to the high local stress during the use of the shims, the stress level may reach the yield strength of detwinned martensite, in which case, the isotropic strengthening model of the von Mises yield criterion is used to describe the plastic deformation of the material; thus,

$$
\sigma_{\text {eq }}-\sigma_{y}\left(\varepsilon_{\text {eq }}^{\mathrm{pl}}\right)=0
$$

where $\varepsilon_{\mathrm{eq}}^{\mathrm{pl}}$ is the equivalent plastic strain, $\sigma_{y}\left(\varepsilon_{\mathrm{eq}}^{\mathrm{pl}}\right)$ is the equivalent plastic stress, and $\sigma_{\mathrm{eq}}$ is the equivalent stress.

\section{Experiment and FEA Method}

\subsection{Experiment}

3.1.1. Sample Preparation. Corrugated samples were prepared by SMA plates with a thickness of $0.3 \mathrm{~mm}$. The material composition is shown in Table 1.

The corrugated samples are shown in Figure 2; the flowchart of corrugated preparation is shown in Figure 3. The cut SMA sheets were placed in a corrugated sample preparation mold (Figure 4), bolted to the upper mold to form corrugations (Figure 3(a)), and placed into a heat treatment furnace for shaping at $500^{\circ} \mathrm{C}$ for 60 minutes, with the heating rate of $4^{\circ} \mathrm{C} / \mathrm{min}$ (Figure $3(\mathrm{~b})$ ). After cooling the furnace, the samples were taken out (Figure 3(c)). The sample sizes are shown in Figure 5. 
TABLe 1: Chemical composition.

\begin{tabular}{lcccccccccc}
\hline $\mathrm{Ni}$ & $\mathrm{Co}$ & $\mathrm{Cu}$ & $\mathrm{Cr}$ & $\mathrm{Fe}$ & $\mathrm{Nb}$ & $\mathrm{C}$ & $\mathrm{H}$ & $\mathrm{O}$ & $\mathrm{N}$ & $\mathrm{Ti}$ \\
\hline 55.59 & 0.005 & 0.005 & 0.005 & 0.012 & 0.005 & 0.046 & 0.001 & 0.03 & 0.001 & Margin \\
\hline
\end{tabular}

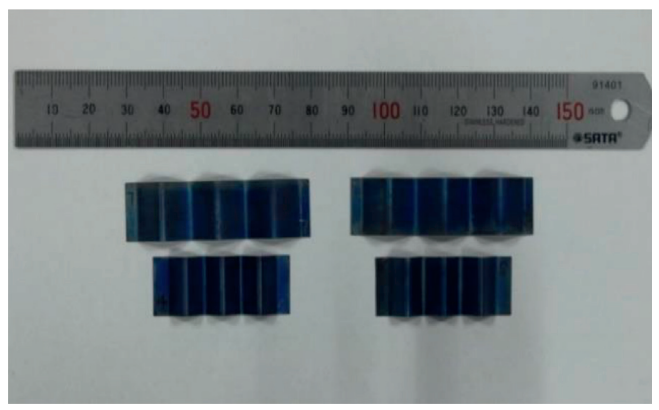

Figure 2: Corrugated samples.

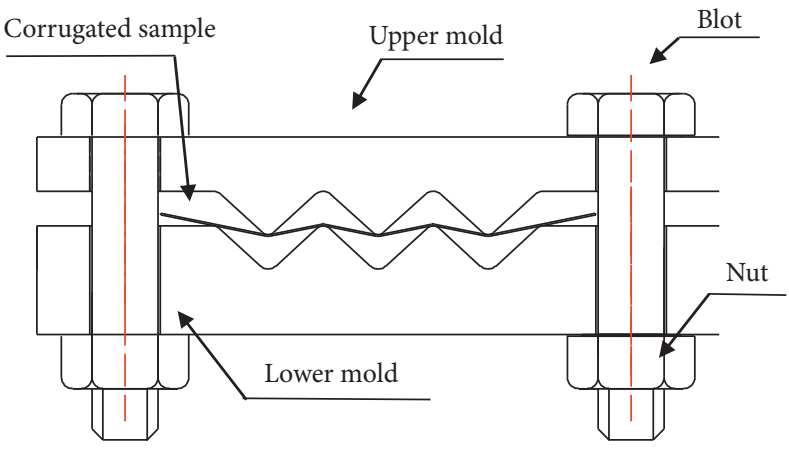

(a)

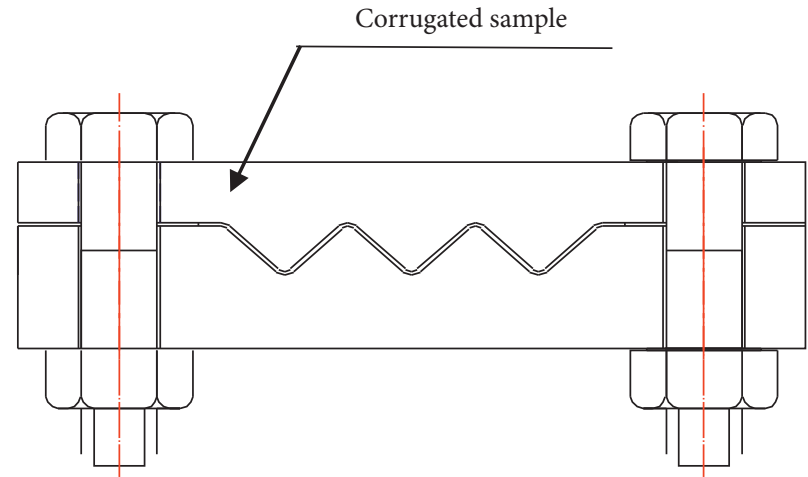

(b)

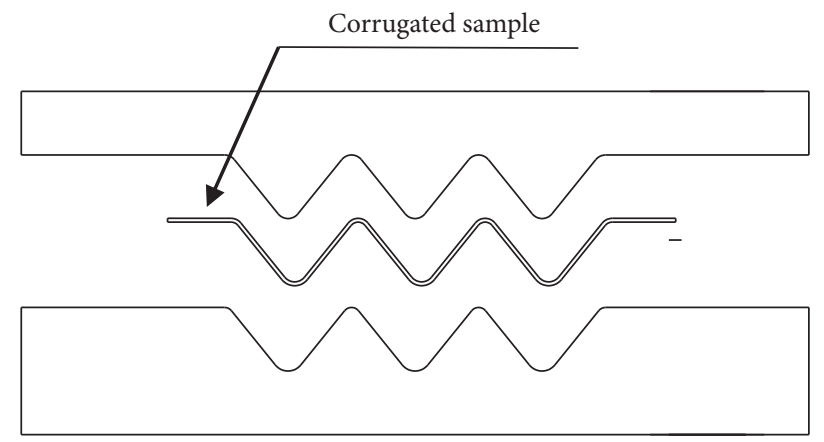

(c)

Figure 3: Flowchart of sample preparation. (a) Clamped at room temperature $\left(25^{\circ} \mathrm{C}\right)$. (b) Shaped at high temperature $\left(500^{\circ} \mathrm{C}\right) .(\mathrm{c}) \mathrm{Released}$ at room temperature $\left(25^{\circ} \mathrm{C}\right)$.

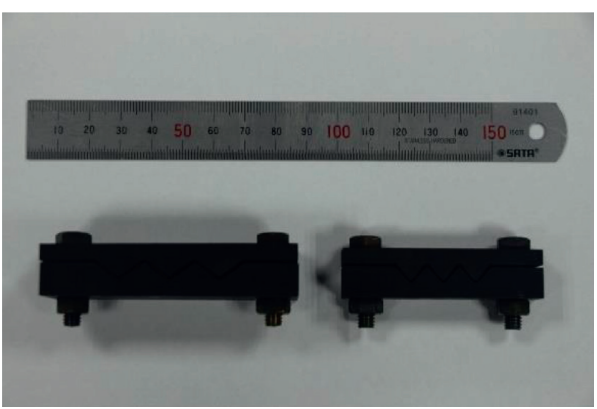

FIGURE 4: Corrugated sample molds.
DSC transformation curve of the samples after heating is shown in Figure 6. The martensite transformation started at $51.2^{\circ} \mathrm{C}\left(M_{s}\right)$ and ended at $37.2^{\circ} \mathrm{C}\left(M_{f}\right)$, and the austenite transformation started at $62.19^{\circ} \mathrm{C}\left(A_{s}\right)$ and ended at $79^{\circ} \mathrm{C}$ $\left(A_{f}\right)$.

3.1.2. Compression-Rebound Mechanical Performance Test Method. To verify the constitutive model of the transformation from twinned martensite to detwinned martensite of SMA-CG under installation conditions, the compression springback of 


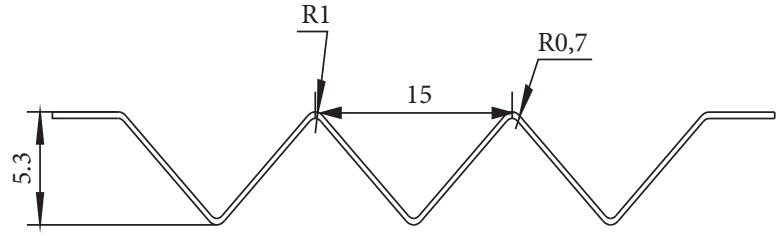

(a)

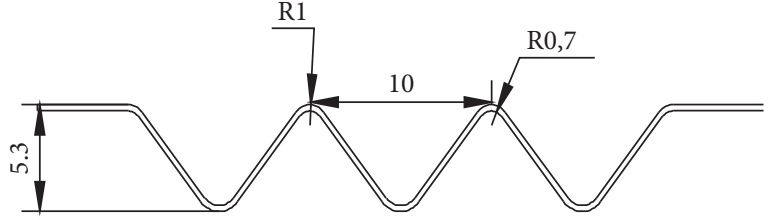

(b)

Figure 5: Structure size of corrugated samples. (a) Large pitch. (b) Small pitch.

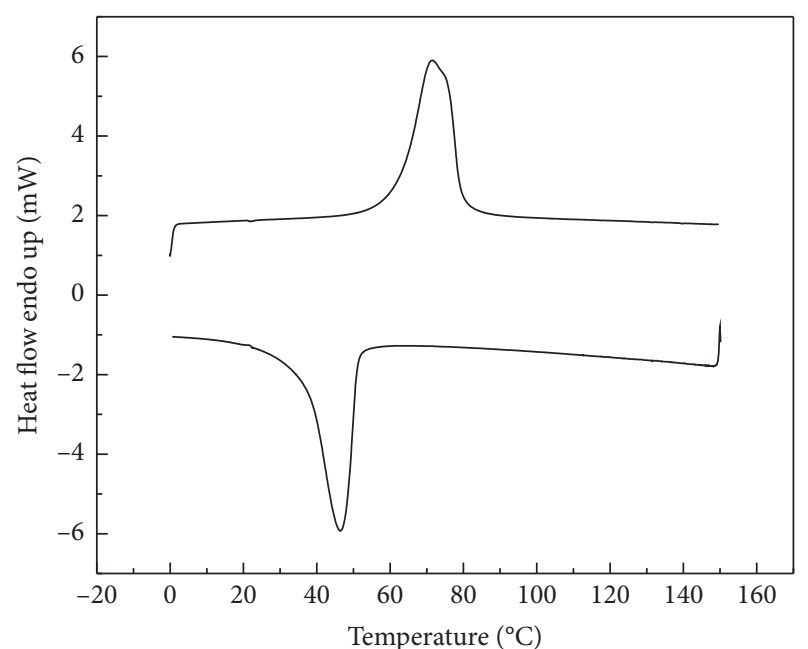

FIGURE 6: DSC phase transformation curve after thermodynamic treatment.

corrugated samples was tested by an Instron 3367 bench electronic testing machine under $60^{\circ} \mathrm{C}$ that was controlled by the environmental chamber. The relative position of SMA-CG and the experimental device is shown in Figure 7.

In the experiment, a displacement loading method was adopted during the loading phase. As shown in Figure 8(a), the position of the lower indenter was kept unchanged, and loading was carried out by changing the displacement of the upper indenter. The maximum compression displacement was $30 \%$ of the height of the corrugated sample. After loading, it was maintained for 5 minutes and then unloaded. As shown in Figure $8(\mathrm{~b})$, force unloading was used in the unloading stage. When the load was $0 \mathrm{~N}$, the unloading stage was completed, and the load versus displacement curve of the upper indenter was recorded. To minimize the influence of mechanical energy on the phase transformation process [23], the strain rate of the compression-rebound test was set to $2.0 \times 10^{-4} \mathrm{~s}^{-1}$.

After the above compression-rebound experiment was completed, as shown in Figure 8(c), the position of upper indenter remained unchanged after unloading to $0 \mathrm{~N}$ (the upper indenter was set to loading displacement, which is $0 \mathrm{~mm}$ ) in order to verify the constitutive model of transformation from detwinned martensite to austenite (SME) under operating conditions, with the temperature increasing from $60^{\circ} \mathrm{C}$ to $A_{f}\left(110^{\circ} \mathrm{C}\right)$ and a heating rate of $3^{\circ} \mathrm{C} / \mathrm{min}$, and the load curve of upper head with temperature was recorded under constant displacement.

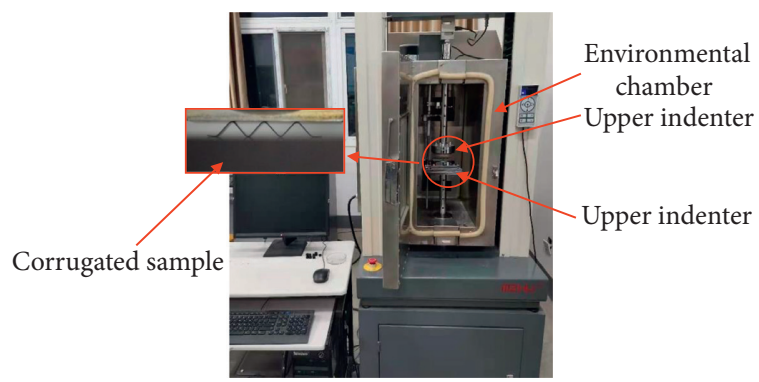

Figure 7: Experimental setup.

3.2. Finite Element Simulation Method. SMA constitutive model was compiled into ABAQUS UMAT subroutine embedded in ABAQUS calculation platform (subroutine flowchart is shown in Figure 9), which was simulated then, and the correctness of constitutive relationship model was verified by comparing finite element calculation results with experimental results. By combining some methods from the work of Kiefer [24], tensile specimens were prepared (Figure 10) and subjected to tensile tests at different temperatures (Figure 11), with tensile test curves processing to obtain material parameters (Table 2), with a yield strength of $500 \mathrm{MPa}$. The finite element geometric model of the SMA corrugated sample is shown in Figure 12(a); C3D8R elements were used for the corrugated sample mesh, to select hourglass reinforced control for ensuring element stiffness, with the mesh quantity of 272,152 . The mesh model is shown in Figure 12(b). Since the deformation of the head during compression and springback is negligible, the upper and lower heads were simplified as rigid bodies. The contact property of penalty functions was adopted between rigid plane and SMA corrugated sample, with the friction coefficient of 0.15 . The analysis step was set as follows.

During the compression and rebound, fixed restraint was applied at the lower pressing head $(\mathrm{U} 1=\mathrm{U} 2=\mathrm{U} 3=\mathrm{UR} 1=\mathrm{UR} 2=\mathrm{UR} 3=0)$, and the boundary condition of the upper indenter was $\mathrm{U} 1=\mathrm{U} 3=\mathrm{UR} 1=\mathrm{UR} 2=\mathrm{UR} 3=0$. For the corrugated samples, the initial temperature field was set in the Predefined Field at $60^{\circ} \mathrm{C}$. In the calculation process, (Step 1 (compression process)) the upper indenter was loaded with downward displacement along U2 direction, with the maximum loading displacement of $30 \%$ of the height in the corrugated sample; (Step 2 (rebound process)) the upper pressure head was unloaded along U2 direction to $0 \mathrm{~N}$.

For the heat recovery, (Step 3 (recovery process)) fixed restraints $(\mathrm{U} 1=\mathrm{U} 2=\mathrm{U} 3=\mathrm{UR} 1=\mathrm{UR} 2=\mathrm{UR} 3=0)$ were used 


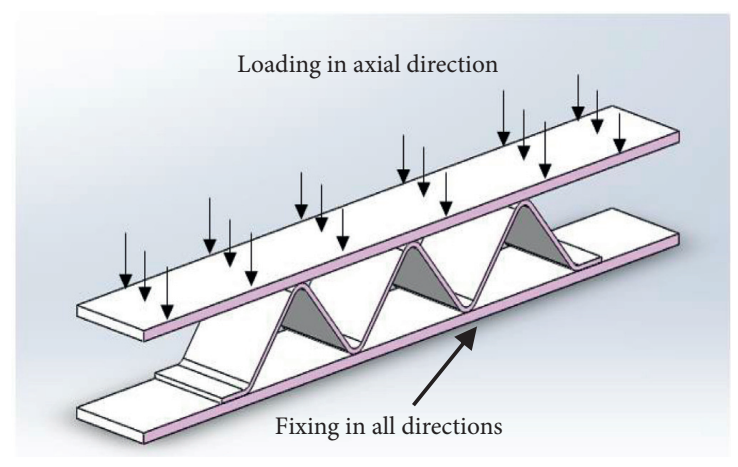

(a)

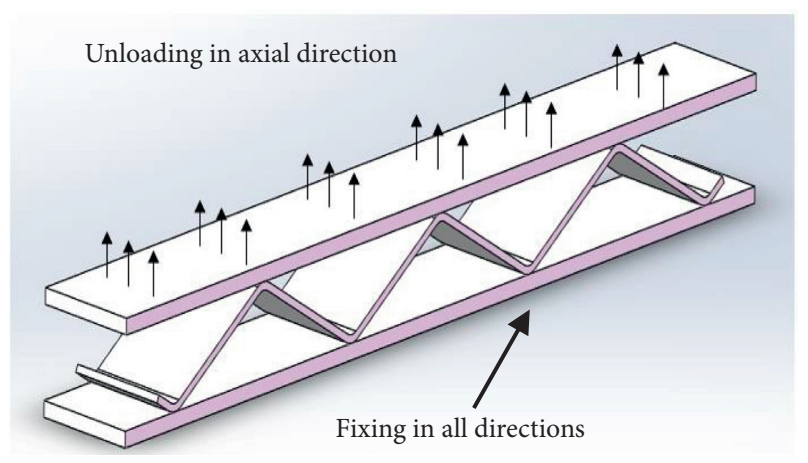

(b)

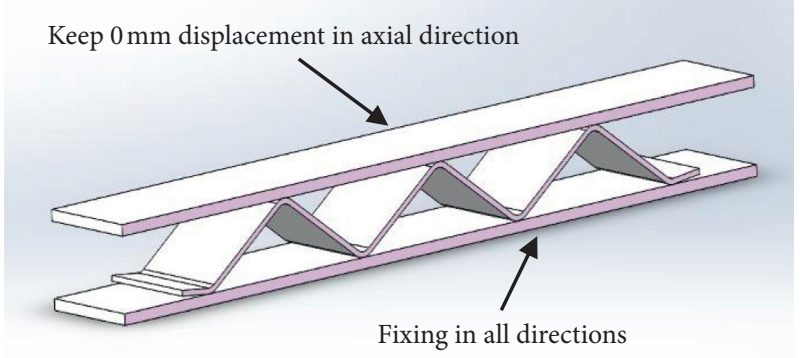

(c)

Figure 8: Experimental flowchart. (a) Load to $1.5 \mathrm{~mm}$ at $60^{\circ} \mathrm{C}$. (b) Unload to $0 \mathrm{~N}$ at $60^{\circ} \mathrm{C}$. (c) Warm up to $110^{\circ} \mathrm{C}$.

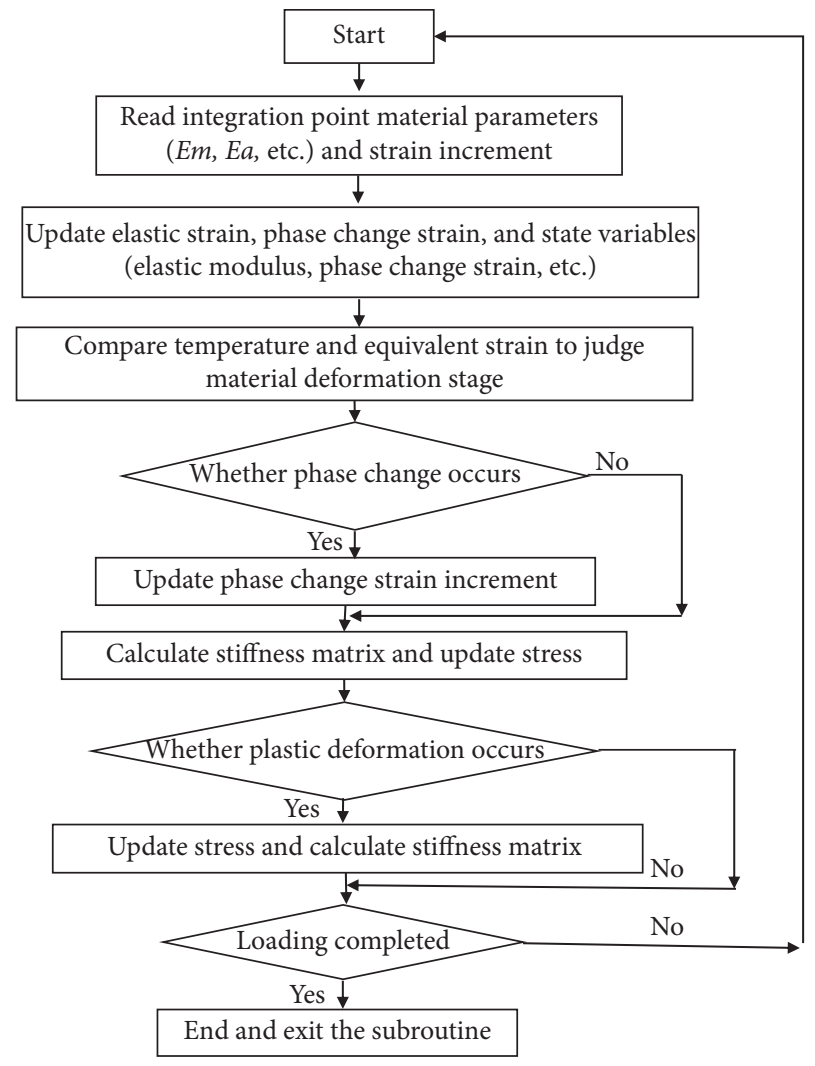

FIGURE 9: Subroutine flowchart.

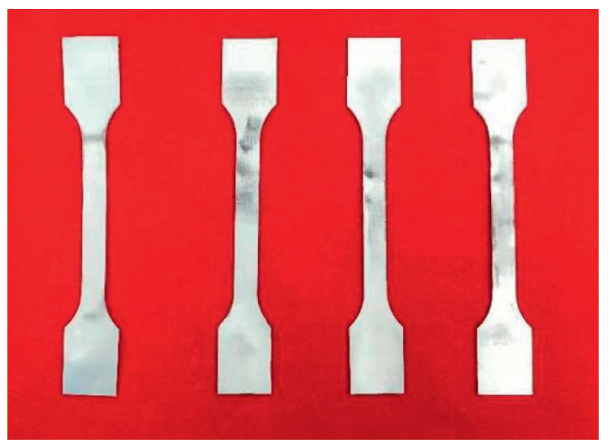

FIgURE 10: SMA tensile test specimen.

on upper and lower indenters, and the temperature field of the corrugated sample was set to $110^{\circ} \mathrm{C}$ in the Predefined Field.

3.3. Comparison of Experimental and Finite Element Results. The curves obtained by experiments and simulations for largespan and small-span corrugated samples are shown in Figures 13 and 14. Figures 13(a) and 14(a) are the load versus displacement curves of the upper indenter obtained by testing machine in loading and unloading experiments. Figures 13(b) and 14(b) show the curve of the load of the upper indenter versus the temperature of environmental chamber under the constraint of constant displacement during heating. 


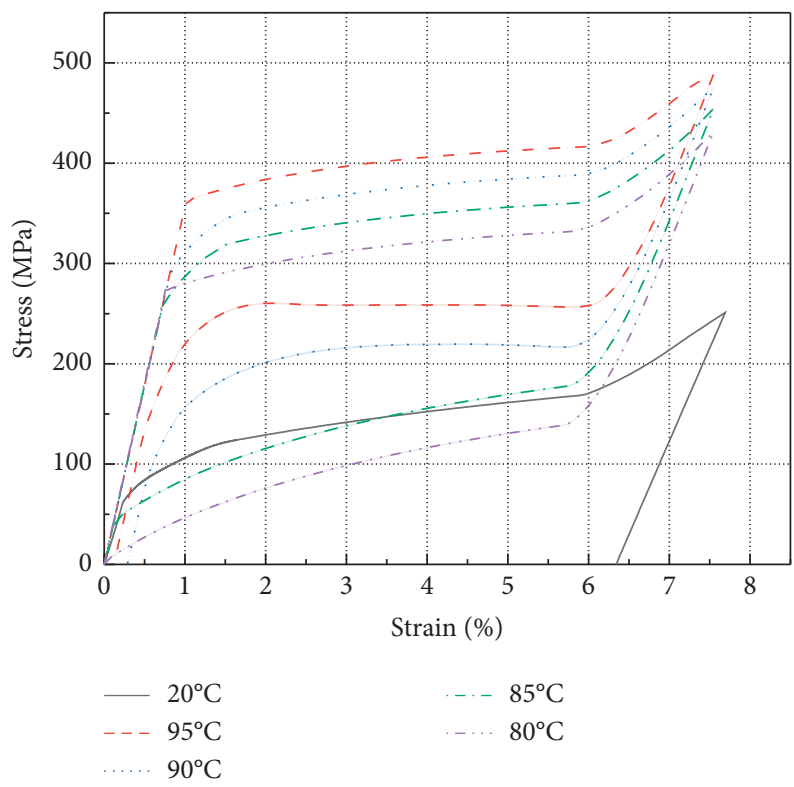

FIGURE 11: SMA stress-strain curve at different temperatures.

TABLE 2: Material parameters of SMA.

\begin{tabular}{lccc}
\hline Moduli & Transformation temperature & Transformation constants & Maximum residual strain \\
\hline$E_{a}=35100 \mathrm{MPa}$ & $M_{f}=310.2 \mathrm{~K}$ & $C_{M}=6 \mathrm{MPa} / \mathrm{K}$ & $\varepsilon_{L}=0.063$ \\
$E_{m}=25000 \mathrm{MPa}$ & $M_{s}=324.2 \mathrm{~K}$ & $C_{A}=8.2 \mathrm{MPa} / \mathrm{K}$ & $\sigma_{S}^{c r}=102 \mathrm{MPa}$ \\
$\theta=0.55 \mathrm{MPa} / \mathrm{K}$ & $A_{s}=335.19 \mathrm{~K}$ & $\sigma_{f}^{c r}=177 \mathrm{MPa}$ & \\
& $A_{f}=352.37 \mathrm{~K}$ & & \\
\hline
\end{tabular}

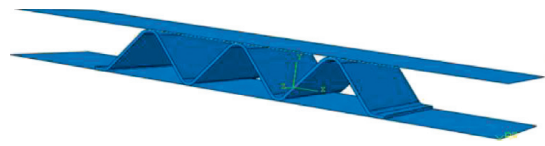

(a)

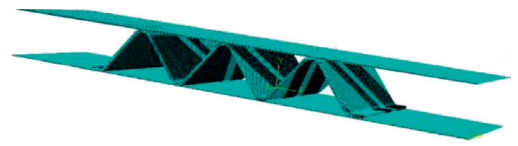

(b)

FIgURE 12: Finite element model of the SMA corrugation experiment. (a) Geometric model. (b) Mesh model.

It can be seen from Figures 13 and 14 that the deformation process of NiTi alloy corrugated sample is divided into six stages: (1) Section $A B$ was the initial loading stage. When corrugated loading occurred, linear elastic deformation initially occurred in the crest region, and the contact area increased. The straight side section was elastically deformed when the load continued, and stress level in the crest region was significantly higher than that of the straight side section. When loaded near point $B$, the stress level in the wave peak region was higher than the transformation stress. The twinned martensite was transformed into detwinned martensite, and the intermediate corrugation was undergoing transformation first. The stress and martensite cloud diagrams are shown in Figure 15(a). (2) In Section BC, the load continued to increase as the phase variable increased. The middle corrugated straight side section underwent bending and deformation under the restrictions of the corrugations on both sides. The sliding velocity of bilateral ripple increases to both sides, bilateral ripple stiffness decreases, and the stress level increases slowly. The stress and detwinned martensite cloud diagrams are shown in Figure 15(b). (3) Section CD was the first half of the unloading stage. In this stage, the elastic bending deformation of straight edge segment of the SMA corrugated sample was recovered first, and then the load dropped rapidly. The stress and detwinned martensite cloud diagrams are shown in Figure 15(c). (4) Section DE was the second half of the unloading section, and in this stage, the opening angle of wave crest was gradually reduced. The residual deformation caused by phase transformation resulted in residual stress, and the deformation generated in the AC stage was not completely recovered. The cloud diagrams of stress and detwinned martensite are shown in Figure 15(d). (5) Section EF was the heating stage. When the temperature was greater than the austenite transformation starting temperature, the single martensite gradually decreased with increasing temperature. The von Mises stress increased due to the constraint of upper and lower plates. The cloud 


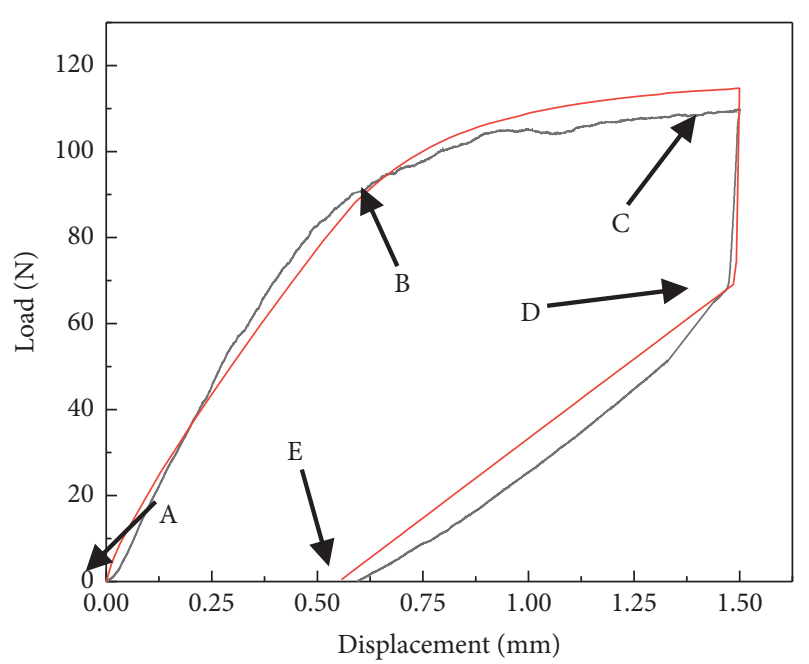

- Experiment

- Simulation

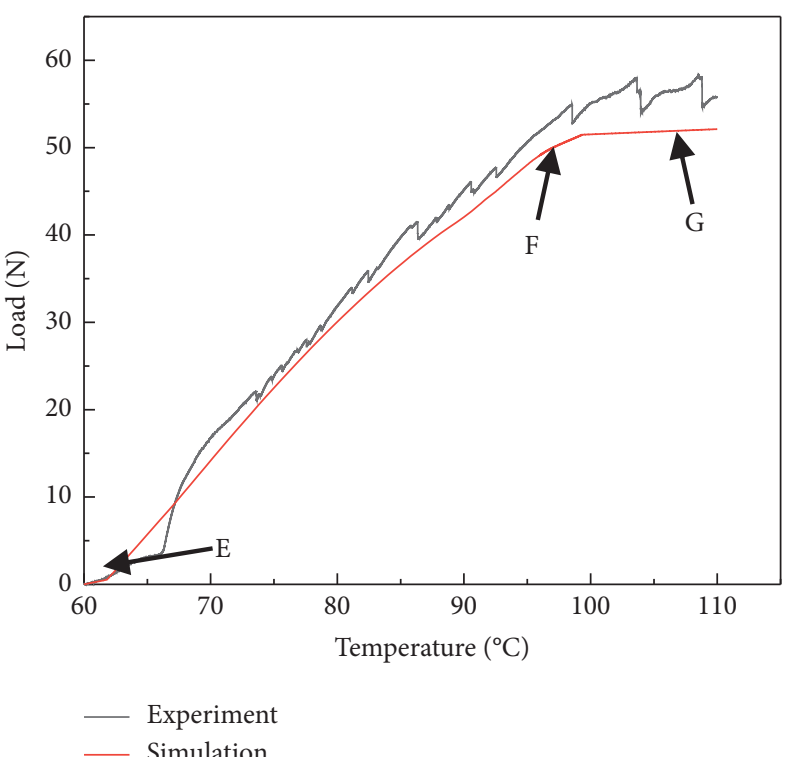

(b)

FIGURE 13: Experiment and simulation curves of large-pitch corrugated sample. (a) Compression-rebound curves of large-pitch corrugated sample. (b) Limited recovery load versus temperature curves for large-pitch corrugated specimen.

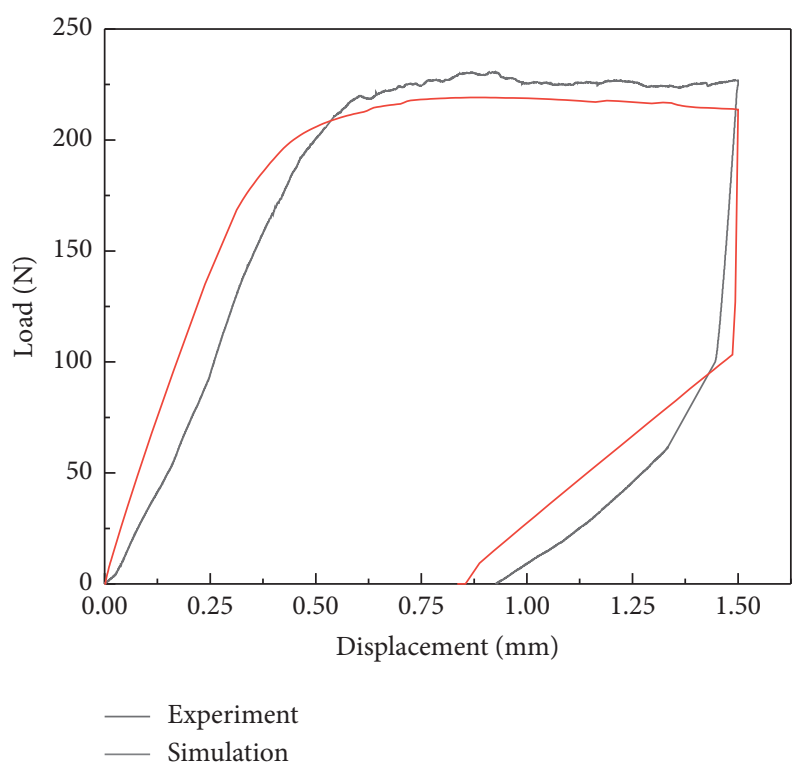

(a)

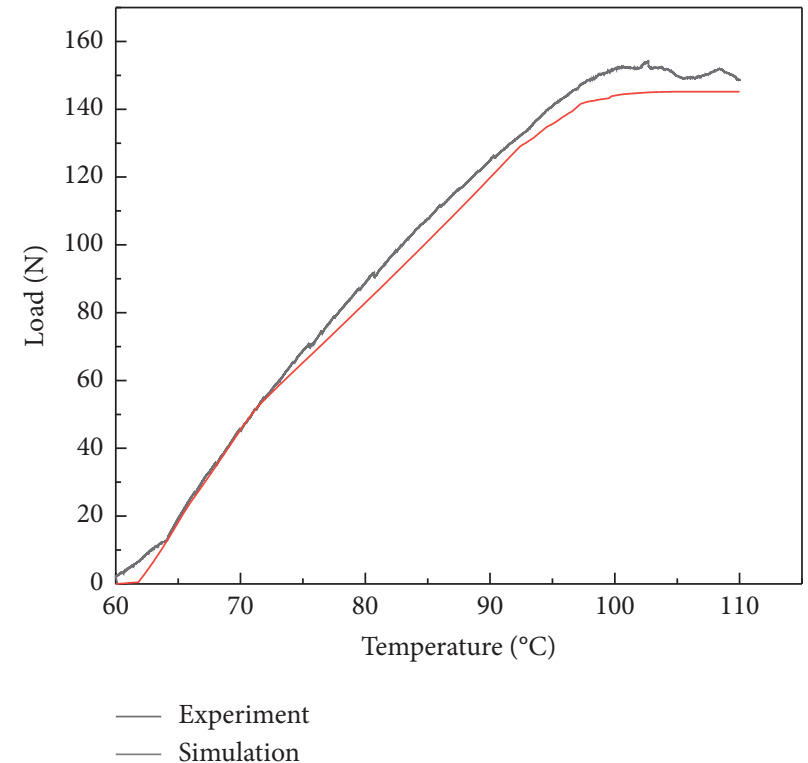

(b)

FIGURE 14: Experiment and simulation curves of small-pitch corrugated sample. (a) Compression-rebound curves of small-pitch corrugated sample. (b) Limited recovery load versus temperature curves for large-pitch corrugated specimen.

diagrams of stress and detwinned martensite are shown in Figure 15(e). The ending temperature of austenite transformation in the thermal recovery was $99^{\circ} \mathrm{C}$, which is higher than $79^{\circ} \mathrm{C}$ as the ending temperature of austenite transformation measured by DSC in the free state, indicating that the recovery stress hindered the reverse transformation of detwinned martensite, due to the existence of constraints. (6) In Section FG, the phase transformation ended as temperature increased. The stress change caused by temperature influence coefficient was much smaller than that caused by phase transformation. The cloud diagrams of stress and detwinned martensite are shown in Figure 15(f). In addition, the experimental and finite element results showed that the maximum compression force of gasket thermal recovery was not less than $40 \%$ of the initial maximum compression load, which indicates that it is helpful to apply SMAs to corrugated gaskets in improving their ability to manage temperature fluctuations. 


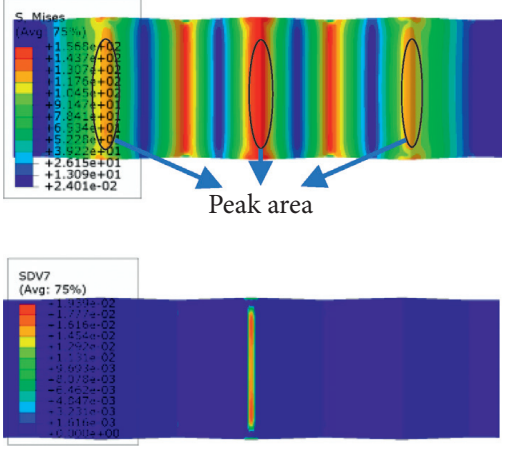

(a)
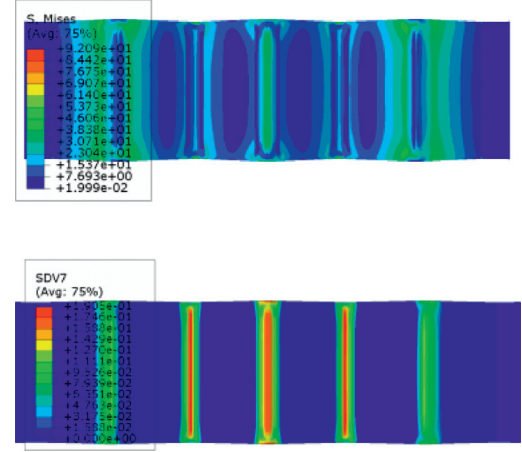

(d)
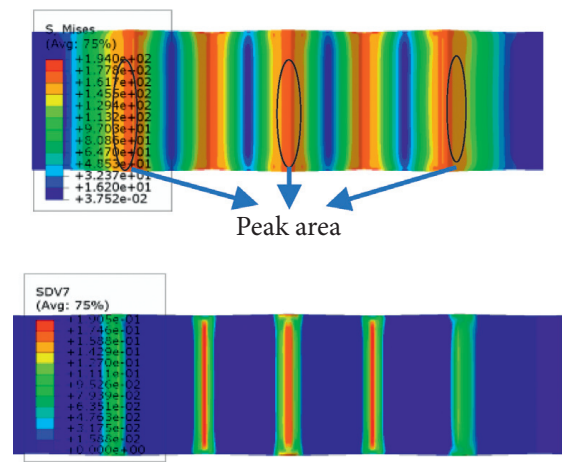

(b)
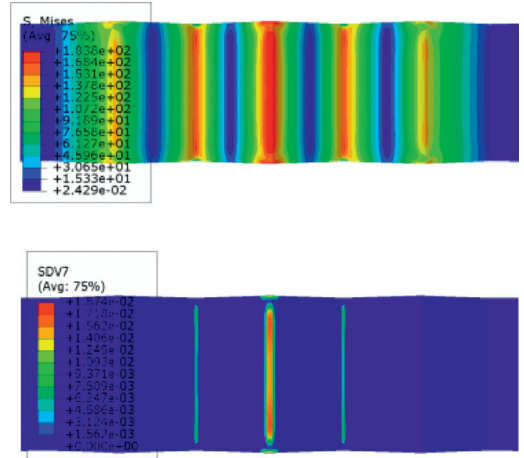

(e)
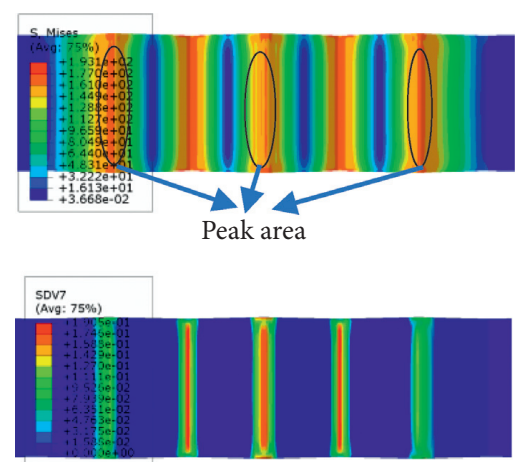

(c)
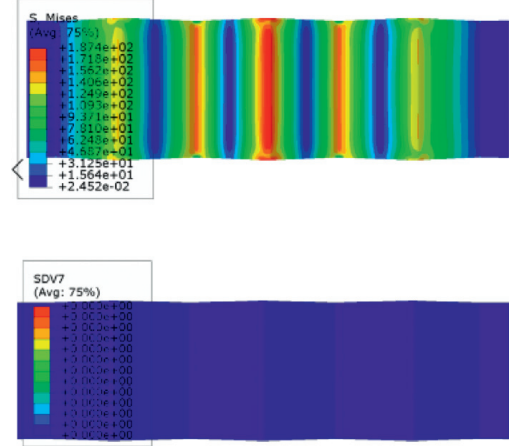

(f)

FIGURE 15: SMA ripple von Mises stress cloud (a, b, c) detwinned martensite cloud (d, e, f): (a) b point cloud; (b) c point cloud; (c) d point cloud; (d) e point cloud; (e) f point cloud; (f) g point cloud.

By comparing the finite element calculation results of compression springback and thermal recovery with the test results in Figures 13 and 14, it can be seen that, under the same strain, the compression springback curves obtained by finite element calculation and test are in good agreement. The maximum compression loads of long-pitch SMA corrugated sample test and finite element simulation were $114.67 \mathrm{~N}$ and $109.77 \mathrm{~N}$, respectively, with an error of $4.27 \%$, rebound rates of $12.20 \%$ and $11.14 \%$, respectively, and an error of $8.69 \%$. The maximum compression forces of the gasket thermal recovery were $58.37 \mathrm{~N}$ and $51.23 \mathrm{~N}$, respectively, with an error of $12.2 \%$. The maximum compression loads of small-pitch SMA corrugated sample test and finite element simulation were $226.86 \mathrm{~N}$ and $213.4 \mathrm{kN}$, respectively, with an error of $5.78 \%$, rebound rates of $18.75 \%$ and $17.09 \%$, respectively, and an error of $8.85 \%$. The maximum compression forces of gasket heat recovery were $145.17 \mathrm{~N}$ and $154.06 \mathrm{~N}$, respectively, with an error of $5.77 \%$. The results indicated that errors between the finite element model-based numerical simulation and experimental results were less than $15 \%$ within the acceptable variation range for engineering fields.

The main errors in this study were experimental errors caused by mechanical performance testing machine and errors between material parameters of finite element simulation and real material parameters of experimental corrugated samples. These particular variations are acceptable in both engineering fields and theoretical models. Therefore, the constitutive model and FEA method proposed in this paper are reasonable, which can be applied in the analysis of mechanical properties of bolted flange SMA-CGs.

\section{Results and Discussion of the Contact Pressure of Gaskets in Flange Joints}

Referring to the above-mentioned FEA method, the influence of structural parameters on the contact pressure of SMA-CGs with bolted flange joints is discussed in this section. The structure optimization design was carried out with the contact stress under operating conditions as the optimization target. CLASS300 band neck butt welding steel flanges were selected according to ASME B16.5-2009 and NPS2 $\frac{1}{2}$. The flange structure size is shown in Figure 16, and the gasket structure size is shown in Figure 17. M20 $\times 8$ double studs were chosen, and due to the axisymmetric characteristics of bolted flange connection structure and load, a 1/8 model including a complete bolt was established (Figure 18(a)). C3D8R elements were used for the flanges, gaskets, and bolts, and the mesh model is shown in Figure 18(b). In the bolted flange connection system, the upper and lower flanges and bolts are made of a linear elastic material. 42CrMo (elastic modulus $E=212000 \mathrm{GPa}$, Poisson's ratio $v=0.284$, and expansion coefficient $=1.34 E-5 / K$ ) was used. The gasket material was SMA, and its material parameters are shown in Table 2. The penalty function contact attributes were adopted between each contact surface, with the friction coefficient of 0.15 . The lower end of lower flange nozzle was set as a fixed support, the two sides of flange were set as axisymmetric restraints, and the upper end of upper flange was 


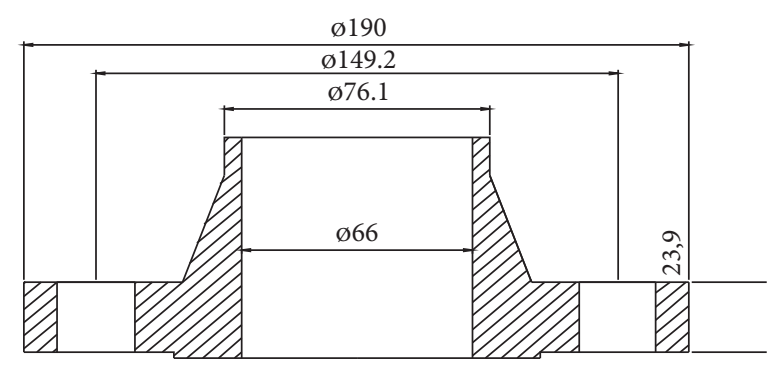

FIGURE 16: Geometry of the butt welding flange joint.

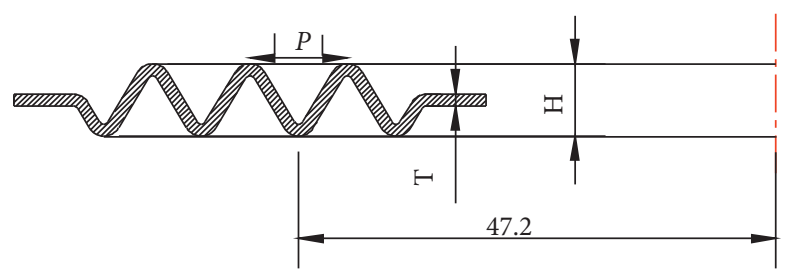

FIgUre 17: Gasket size.

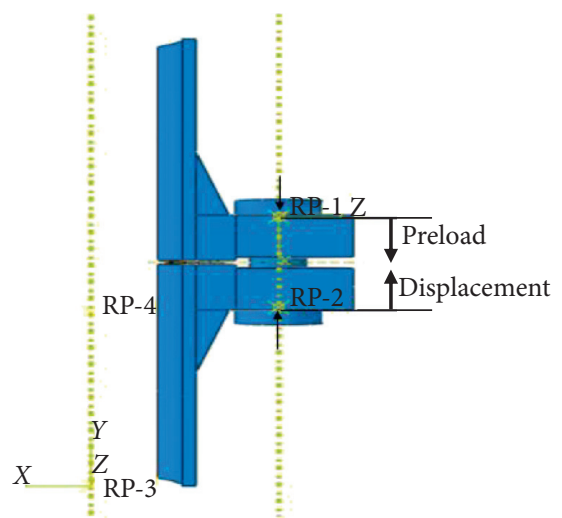

(a)

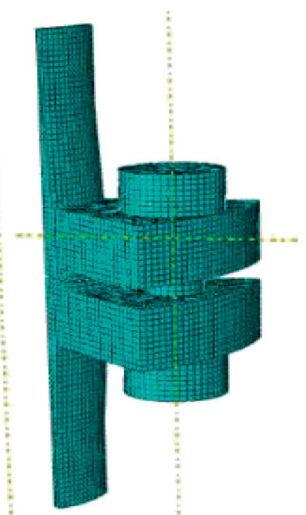

(b)

Figure 18: The finite element model of the SMA-CG with bolted flange joints. (a) Geometric model. (b) Mesh model.

free. According to Saint-Venant's theorem, in consideration of the boundary effect, the flange connection length was larger than $2.5 \sqrt{R T}$, where $R$ is the pipe radius and $T$ is the pipe wall thickness. The installation and service conditions of bolted flange connection system were simulated, assuming that the bolted flange connection joint was in a uniform temperature field [4]. The analysis steps were set as follows (Table 3):

Step 1 (installation condition): an initial temperature of $30^{\circ} \mathrm{C}$ was set for the flanges, gasket, and bolt in the Predefined Field, and then pretightening forces were applied. Since the bearing capacity of SMA corrugated gaskets varies with different structures, a displacement constraint along the bolt axis as shown in the figure is applied to the bolt, and the displacement is $10 \%$ of the corrugated height as shown in Figure 18(a). Step 2 (service condition application of internal pressure): keep the length of the bolt; an internal pressure load of $5 \mathrm{MPa}$ was applied to the inner wall of the upper and lower flanges and the upper end surface of the upper flange.
Step 3 (service condition application of temperature load): a uniform temperature field was applied to the flanges, gasket, and bolt, the temperature was set to $120^{\circ} \mathrm{C}$ in the Predefined Field, and during the heating process, the temperature increased linearly and uniformly to $120^{\circ} \mathrm{C}$ with time.

For flange sealing connections, the most immediate problem that affects the sealing effect is "leakage." The leakage of gaskets includes penetration leakage and interface leakage. In flange connections using metal gaskets, only interface leakage is present. The problem corresponding to the interface leakage is the sealing pressure, that is, the contact stress between the gasket and the flange. The sealing contact stress is an essential technical parameter that affects the sealing performance.

According to its structure, SMA-CG forms a line seal with the flange under the action of bolt load and forms three concentric seal rings with the upper flange, as shown in Figure 19(a), and two concentric sealing rings are formed 
Table 3: The step set.

\begin{tabular}{lcc}
\hline \multicolumn{1}{c}{ Analysis step } & Loading process \\
\hline Preload condition & Step 1 & Installation at $30^{\circ} \mathrm{C}$ (bolt pretightening) \\
Installation conditions & Step 2 & Keep the length of the bolt, add internal pressure $(5 \mathrm{MPa})$ \\
& Step 3 & Keep the length of the bolt and heat up to $120^{\circ} \mathrm{C}$ at $5 \mathrm{MPa}$ \\
\hline
\end{tabular}

with the lower flange, as shown in Figure 19(b). In the following section, the influence of structural parameters of SMA-CGs (thin plate thickness $T$, gasket thickness $H$, and pitch $P$ ) on the contact pressure between gaskets and upper and lower flanges will be discussed.

\subsection{Single Factor Analysis of the Structural Parameters}

4.1.1. Influence of SMA-CG Sheet Thickness on Contact Pressure. The influence of sheet thickness $T$ on contact pressure was explored by taking a corrugated gasket with height $H=2.5$, pitch $P=3$, and sheet thicknesses $T=0.3 \mathrm{~mm}$, $0.4 \mathrm{~mm}, 0.5 \mathrm{~mm}$, and $0.6 \mathrm{~mm}$, respectively (Figure 20).

It can be seen from Figure 20 that the contact pressures of corrugation A and corrugation C first decreased and then increased with increasing sheet thickness under the pretightening and internal pressure of bolts, which was due to the sheet thickness being $\leq 0.4 \mathrm{~mm}$, and the lesser radial stiffness of the SMA-CG. When subjected to the compression load outside the plane, corrugations $\mathrm{A}$ and $\mathrm{C}$ slid along the radial direction, and their deformations were dominated by the overall opening of the corrugations. When the sheet thickness was $>0.4 \mathrm{~mm}$, the radial stiffness increased as sheet thickness increased, and the restraint on the inner and outer edges of the corrugation increased. The local deformations of corrugations $\mathrm{A}$ and $\mathrm{C}$ became the main deformation mode, resulting in the contact stress showing an initial decreasing trend followed by an increasing trend. The contact pressure of corrugation B gradually rose with increasing thickness related to the local deformation at the wave crest and the bending deformation of straight edge segment becoming the main deformation mode of corrugation $\mathrm{B}$. As sheet thickness increased, the bending stiffness of the straight edge of corrugation B and wave crest increased, resulting in increased contact stress as sheet thickness increased. The contact pressure of corrugation $\mathrm{D}$ increased with increasing corrugation thickness primarily due to the increased bending stiffness of corrugation $\mathrm{D}$ as sheet thickness increased. Since the deformation mode was dominated by local deformation in the crest region, the contact pressure of corrugation D increased with increasing sheet thickness, and the contact pressure of corrugation $\mathrm{E}$ first decreased and then rose with increasing sheet thickness. Corrugation E was located on the inside of the corrugated gasket, which was less constrained by the bending moment of the flange surface. Therefore, when the thickness of the thin plate was $0.4 \mathrm{~mm}$, the corrugation slipped similar to the deformations of corrugations A and C. For corrugation E, the thickness increased as corrugation radial stiffness increased, and since the deformation mode was dominated by local deformation in the crest region, the contact pressure of corrugation $\mathrm{E}$ first decreased and then increased with increasing sheet thickness.

As seen from Figure 20, after the temperature rose, the contact stress at the peaks of corrugations A, B, C, D, and E increased with increasing sheet thickness due to the transformation of detwinned martensite into austenite at the wave peak and the higher elastic modulus of austenite than that of detwinned martensite. The bending stiffness of the peak region increased with increasing sheet thickness, leading to increased contact pressure. When sheet thickness increased, the contact stress in peak regions of ripples $\mathrm{B}, \mathrm{C}, \mathrm{D}$, and $\mathrm{E}$ increased nonlinearly, which can be explained by the fact that flexural stiffness was proportional to the thickness raised to the third power. The contact stress for corrugation A, however, appeared linear, possibly due to the slip deformation formed along the radial direction and the bending deformation of wave peak area, both of which occurred during the deformation process of corrugation $\mathrm{A}$.

\subsubsection{Influence of SMA-CG Height on Contact Pressure.} The influence of gasket height $\mathrm{H}$ on contact pressure was examined by taking a corrugated gasket with sheet thickness $T=0.4 \mathrm{~mm}$, pitch $P=3 \mathrm{~mm}$, and gasket heights $H=2 \mathrm{~mm}$, $2.5 \mathrm{~mm}, 3 \mathrm{~mm}$, and $3.5 \mathrm{~mm}$, respectively (Figure 21).

It can be seen from Figure 21 that the contact pressure of each corrugation showed an upward trend with increasing corrugation height during the applications of bolt pretension and internal pressure, because as height increased, the corresponding corrugation angle decreased, while radial stiffness and load-bearing capacity increased. With the increase of the height of the gasket, the contact pressure of each corrugated segment increases. When the height of corrugation A reached $2.5 \mathrm{~mm}$, the contact pressure level began to drop, since the radial stiffness of corrugation $\mathrm{A}$ was less than its bending stiffness during the deformation process, resulting in the slip deformation along the radial direction. The contact pressures of corrugations $\mathrm{B}$ and $\mathrm{E}$ increased more obviously with increasing height, as they were more obviously constrained by the inner and outer corrugations.

According to Figure 21, the contact pressures of corrugations $\mathrm{A}$ and $\mathrm{C}$ first decreased and then rose with increasing corrugation height under high temperature conditions, which was mainly due to the increasing phase change areas of corrugations $\mathrm{A}$ and $\mathrm{C}$ as height increased. When height was $\leq 3 \mathrm{~mm}$, the transverse load generated by the phase change recovery stress on the straight edge segment was greater than the sliding resistance. The deformations of corrugations $\mathrm{A}$ and $\mathrm{C}$ were mainly caused by the expansion of the corrugations, and contact pressure decreased. When height was $>3 \mathrm{~mm}$, due to the axial load, 


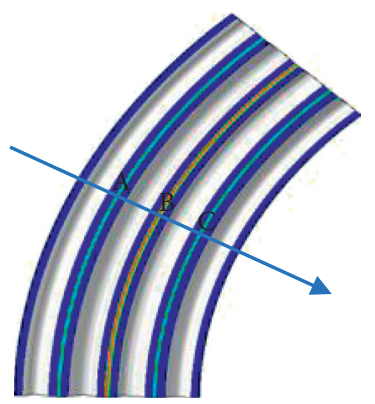

(a)

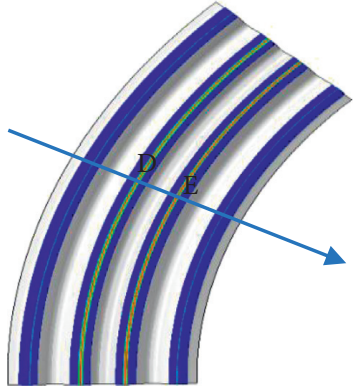

(b)

Figure 19: Contact stress distribution on the sealing surfaces. (a) Upper sealing surface. (b) Lower sealing surface.
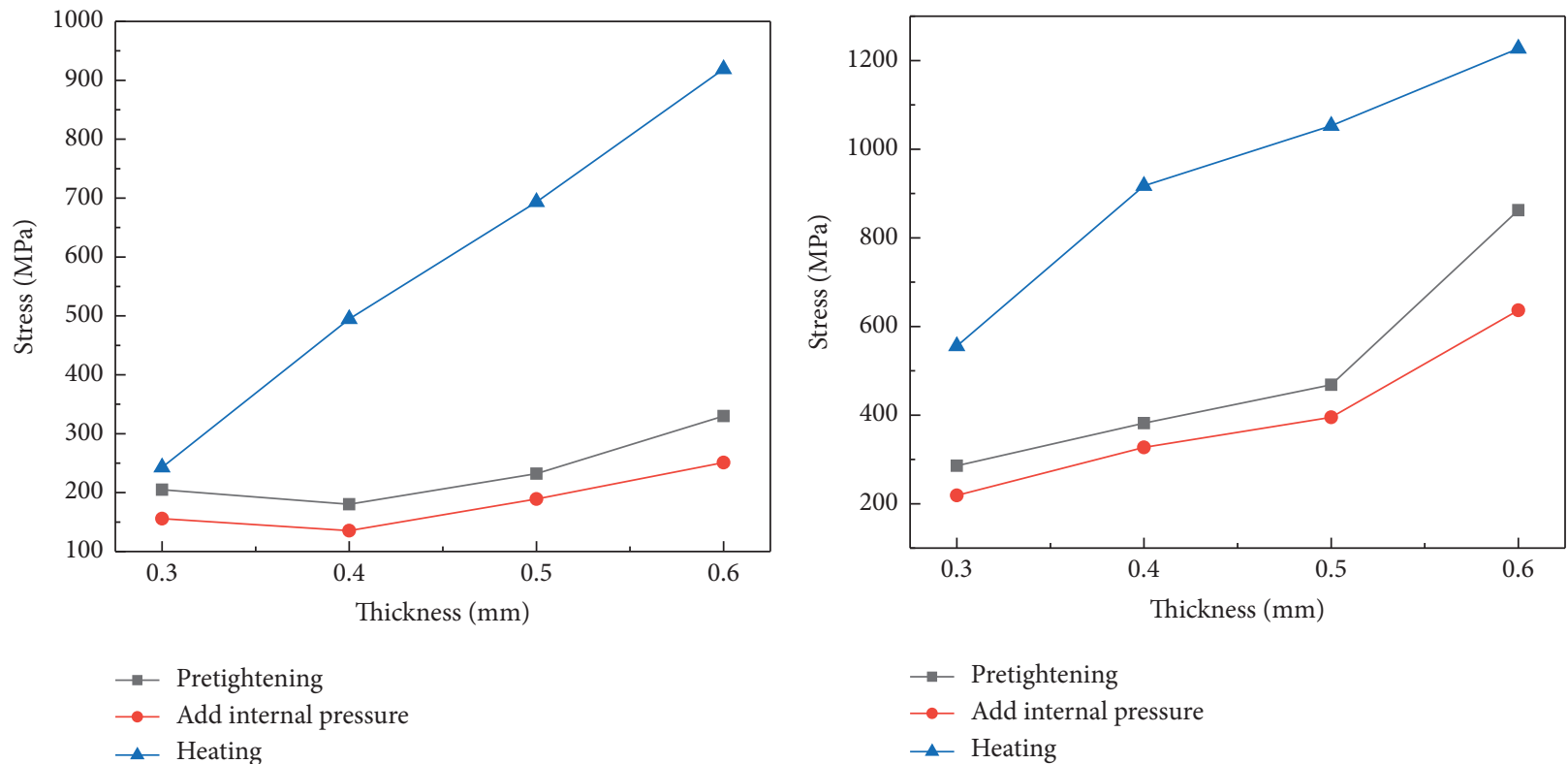

(a)

(b)
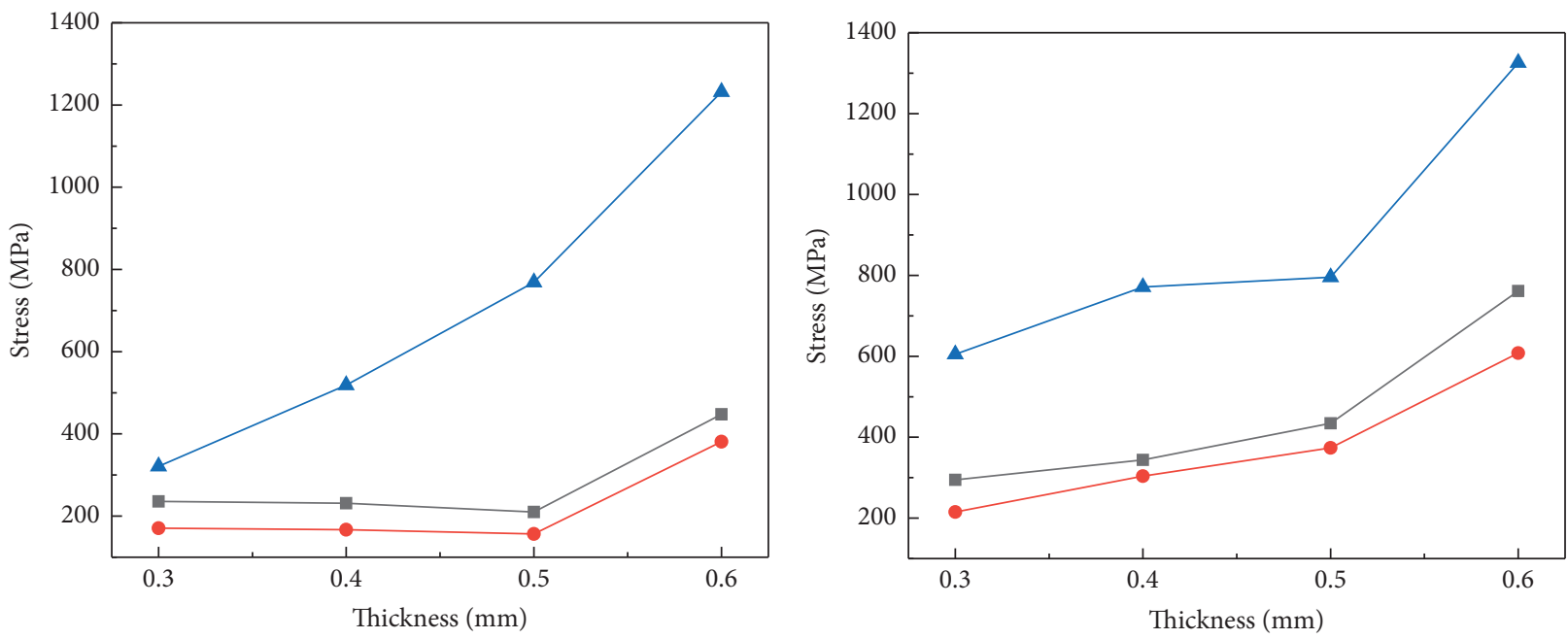

$\multimap$ Pretightening
$\multimap-$ Add internal pressure
$\_$Heating

$\rightarrow$ Pretightening
$\rightarrow$ Add internal pressure
$\multimap$ Heating

(c)

Figure 20: Continued. 


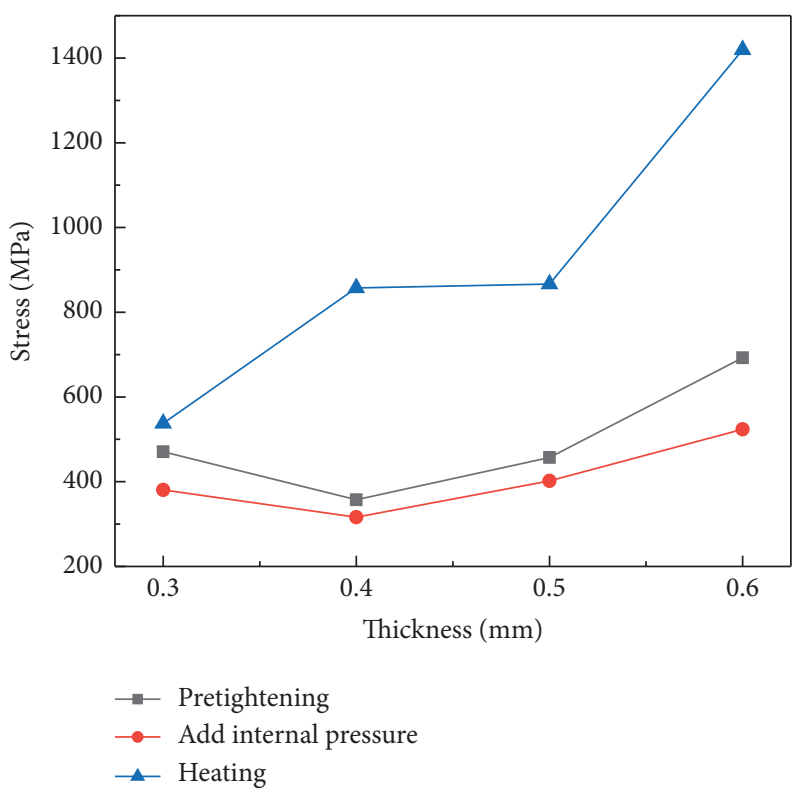

(e)

Figure 20: Contact pressure trends of various corrugations in different states in regard to sheet thickness. (a) Corrugation A.

(b) Corrugation B. (c) Corrugation C. (d) Corrugation D. (e) Corrugation E.

transverse slip resistance and radial stiffness increased, and contact pressure also increased, resulting in the contact pressures of corrugations $\mathrm{A}$ and $\mathrm{C}$ first decreasing and then increasing. At high temperatures, the contact pressure of corrugation $\mathrm{B}$ first rose and then decreased, which was mainly due to the deformation of corrugation $\mathrm{B}$ being opposite to those of corrugations A and C. During the initial stage, due to the constraints of corrugations $\mathrm{A}$ and $\mathrm{C}$, the deformation of corrugation $\mathrm{B}$ was mainly local deformation in the peak region, and as stiffness increased, the contact compressive stress also increased. With increasing height, obvious plastic deformation occurred in the peak area of corrugation $\mathrm{B}$ under the pretightening state and internal pressure state, and load-bearing capacity decreased, leading to an initial rising trend followed by a decreasing trend for the contact pressure of corrugation $\mathrm{B}$. The contact pressure of corrugation D increased with increasing height, due to the increase in phase transition recovery stress generated at the first and second stages of the wave crest, and as corrugation stiffness increased, contact pressure also increased. The contact pressure of corrugation E fluctuated with increasing height, which may be related to the variation trend of corrugation $\mathrm{B}$, and the coupling effect of the phase transformation recovery of corrugation $\mathrm{E}$.

4.1.3. Influence of SMA-CG Pitch on Contact Pressure. The influence of gasket span $\mathrm{P}$ was investigated by taking a corrugated gasket with sheet thickness $T=0.4 \mathrm{~mm}$, height $H=3 \mathrm{~mm}$, and gasket pitches $P=2.5 \mathrm{~mm}, 3 \mathrm{~mm}, 3.5 \mathrm{~mm}$, and $4 \mathrm{~mm}$, respectively (Figure 22). As seen from Figure 22, the contact pressures of corrugations $\mathrm{A}, \mathrm{B}, \mathrm{C}, \mathrm{D}$, and $\mathrm{E}$ decreased with increasing pitch under pretightening and internal pressure states. As pitch increased, the corresponding angle of each ripple increased while radial stiffness decreased. Under the action of out-of-plane loads, the transverse load of the straight edge segment increased, the corrugation deformation was mainly open, and the contact pressure of each corrugation decreased as bearing capacity decreased.

As seen from Figure 22, the contact pressures of corrugations $\mathrm{A}, \mathrm{C}, \mathrm{D}$, and $\mathrm{E}$ tended to decrease as corrugation pitch increased under high temperature conditions, due to the decreasing radial stiffness of the corrugations as pitch increased. Furthermore, with increasing pitch, the required transverse load for the corrugations to expand and deform as a whole decreased, the phase transition region decreased with decreasing contact pressure in the first and second stages, and phase transition recovery stress also decreased. The contact pressure of corrugation B fluctuated with increasing corrugation pitch, which was mainly because as pitch increased, the required transverse load for the overall expansion of the corrugation, the deformation stiffness of the corrugation, and the required restoring stress for corrugation arching all decreased. Moreover, the phase transition area of corrugation $B$ was significantly larger than that of corrugations A and C. Therefore, as pitch increases, the deformation mode between the overall corrugation expansion and corrugation arching changes, and the corrugated contact pressure fluctuates.

4.2. Analysis of Range and Variance of the Structural Parameters of SMA-CGs. According to the single factor analysis results, the average contact pressure of the SMA-CG after heating was taken as the design index, and the threefactor and three-level structural parameters shown in Table 4 were selected for the orthogonal design. From this, the 


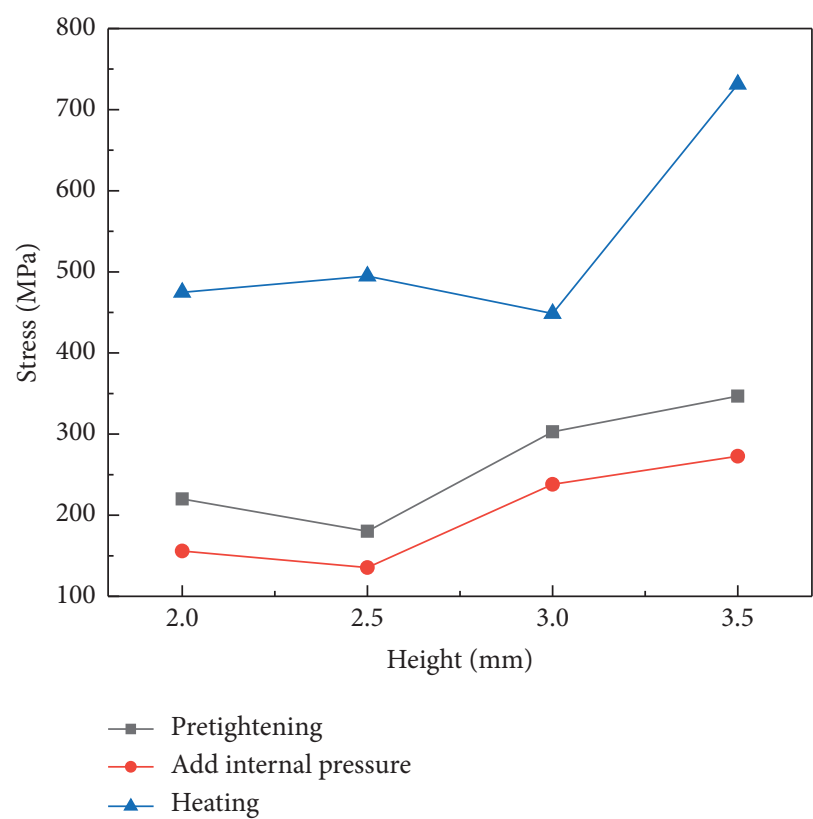

(a)

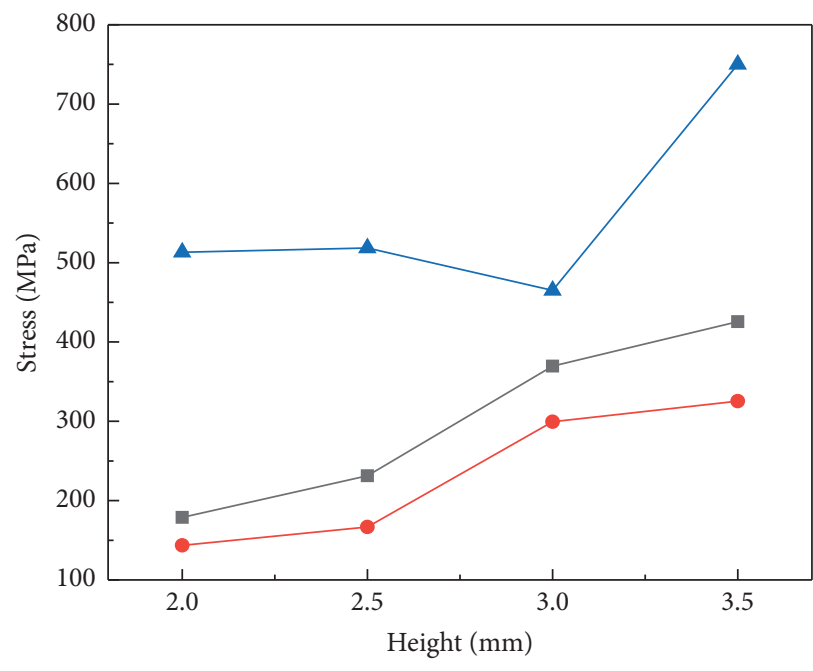

- Pretightening

- Add internal pressure

$\neg$ Heating

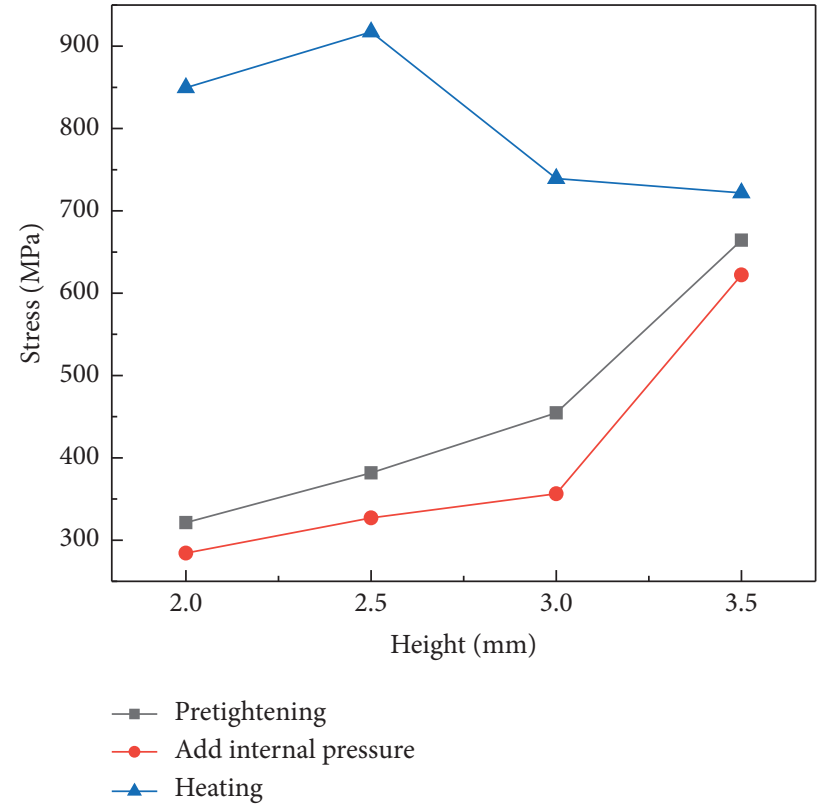

(b)

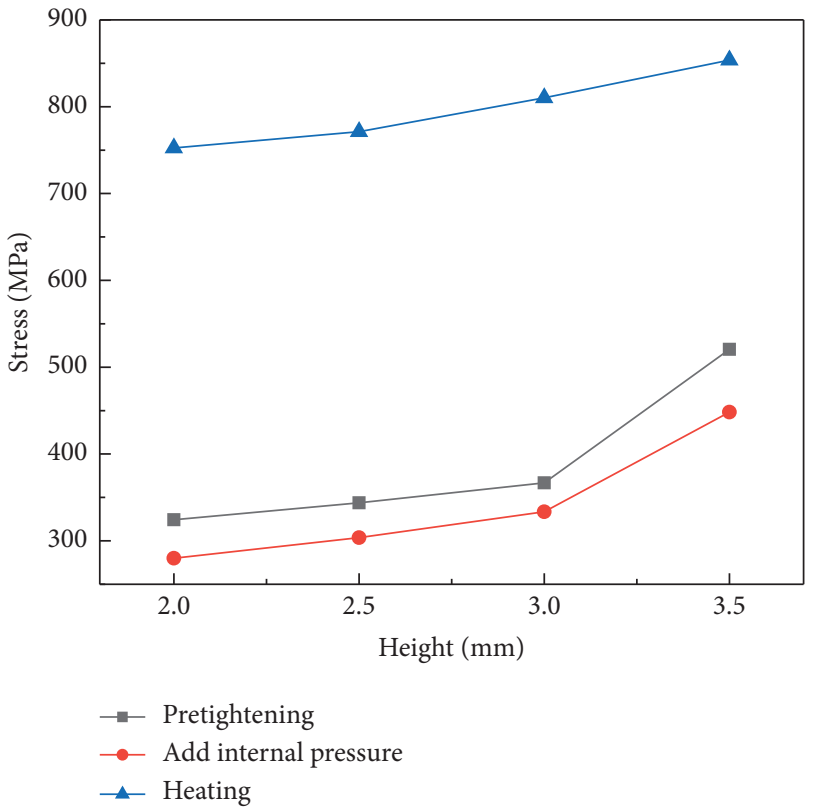

(d)

Figure 21: Continued. 


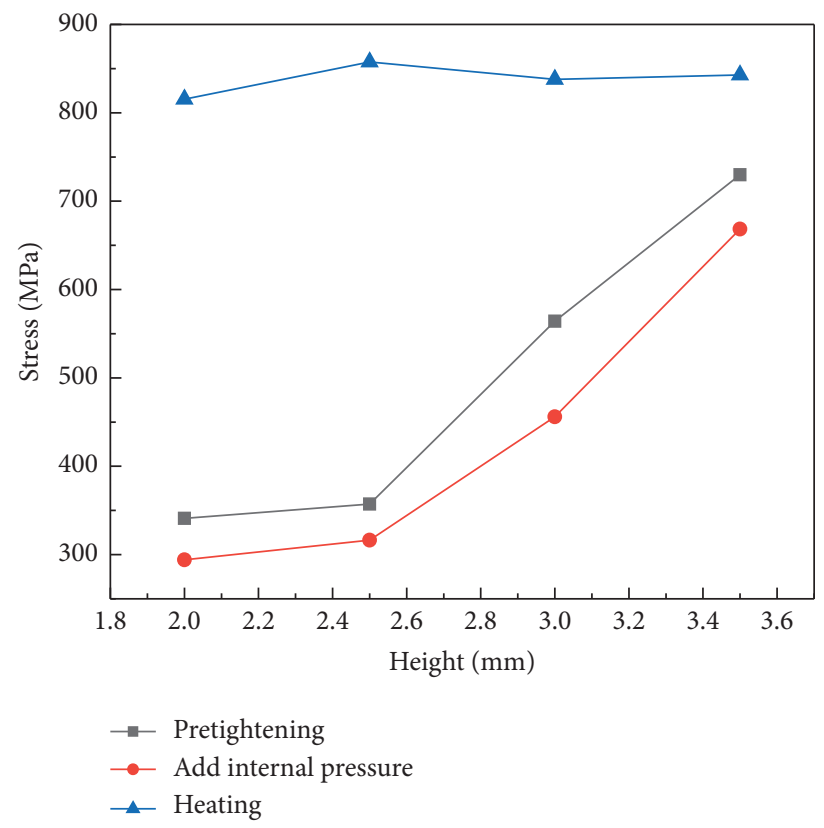

(e)

Figure 21: Contact pressure trends of various corrugations in different states in regard to height. (a) Corrugation A. (b) Corrugation B. (c) Corrugation C. (d) Corrugation D. (e) Corrugation E.

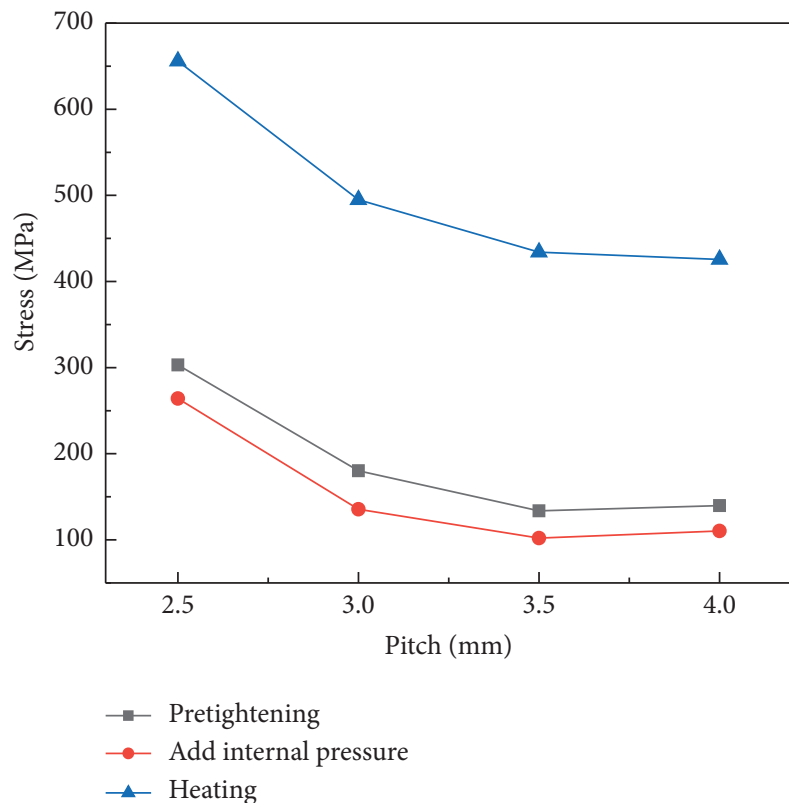

(a)

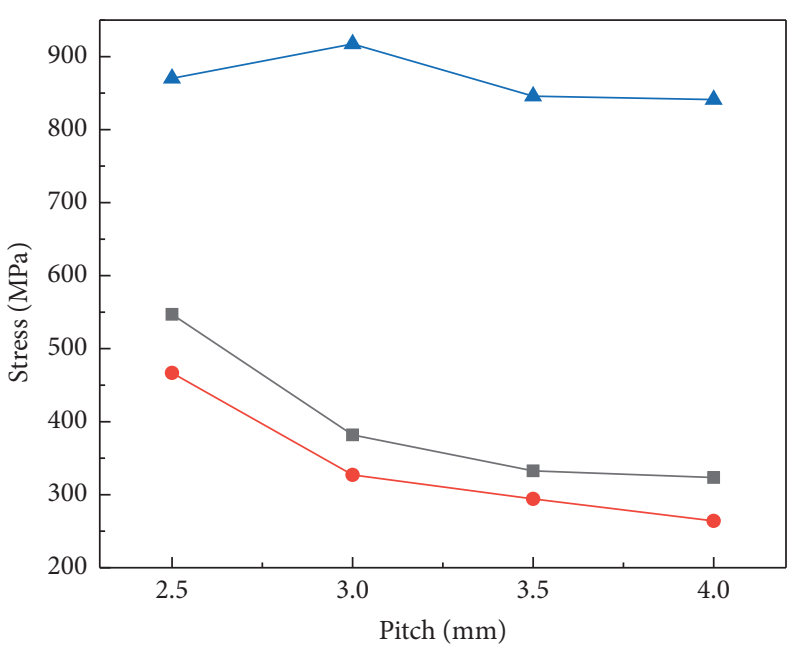

$\_$Pretightening
$\multimap-$ Add internal pressure
$\_$Heating

(b)

Figure 22: Continued. 

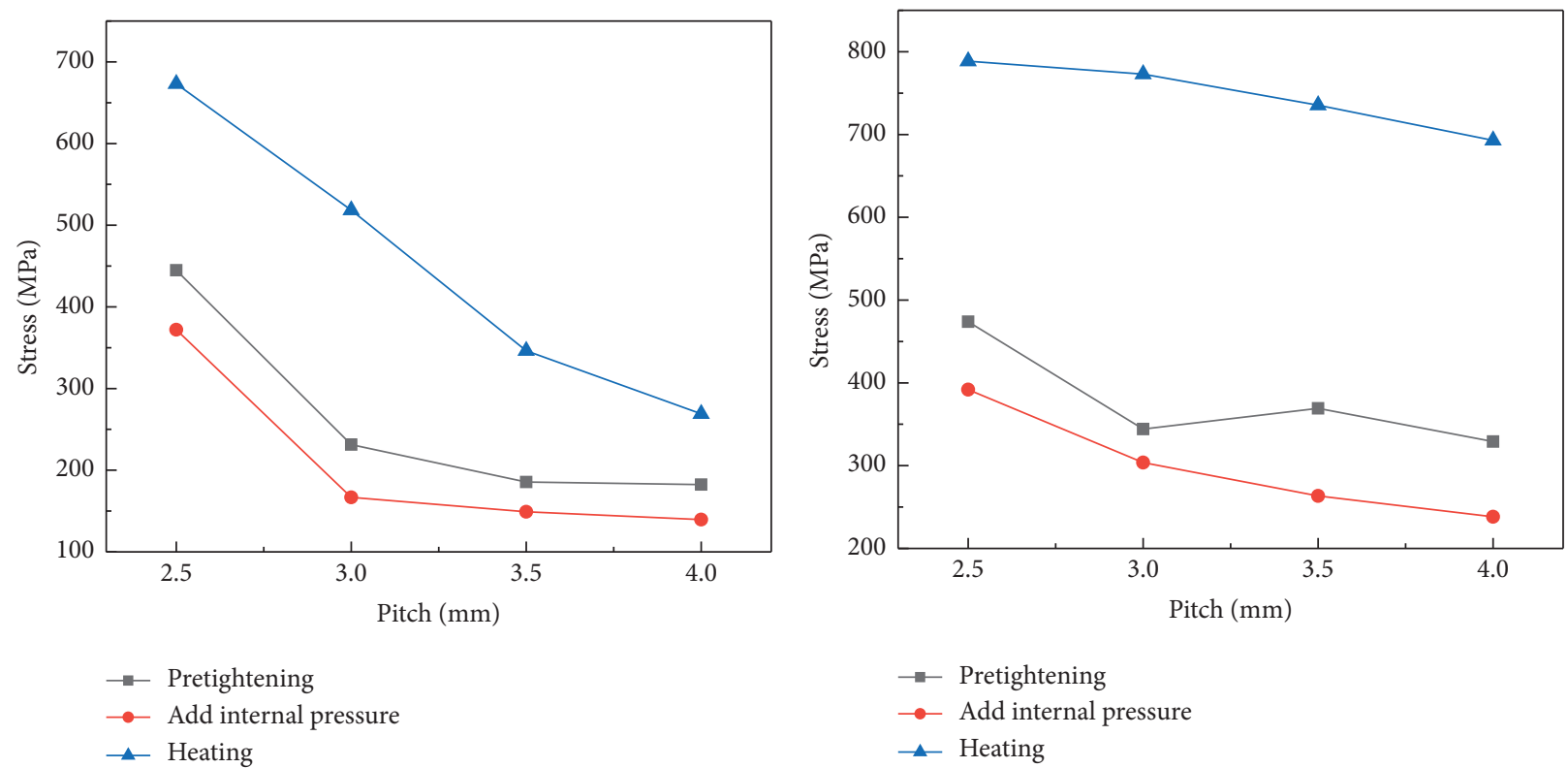

(c)

(d)

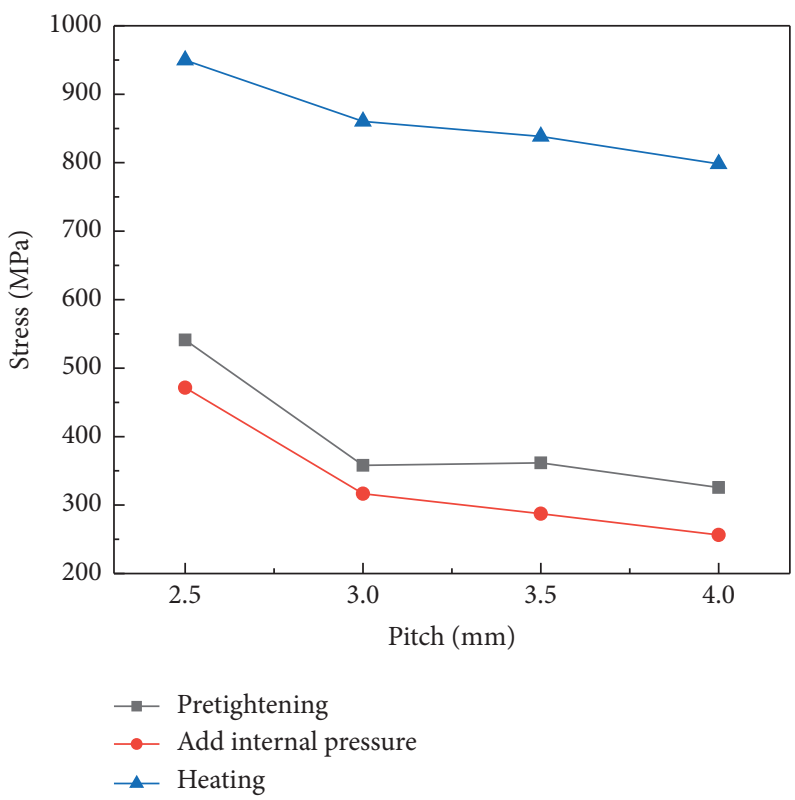

(e)

Figure 22: Contact pressure trends of various corrugations in different states in regard to pitch. (a) Corrugation A. (b) Corrugation B. (c) Corrugation C. (d) Corrugation D. (e) Corrugation E.

L9 $\left(3^{4}\right)$ standard orthogonal analysis design table was established. The experimental group and results are shown in Table 5. The results of orthogonal experiments in Table 5 were analyzed for variance and range.

The range analysis of gasket average contact pressure can be found in Table 5. It can be seen from the range that sheet thickness had the greatest influence on average contact pressure, followed by gasket height and corrugation pitch.

Using STATISTICA statistical analysis software, the experimental results were analyzed by variance, and the results are shown in Table 6 . It can be seen that the $P$ values of sheet thickness, gasket height, and corrugation pitch were all $<0.05$, indicating that the results are statistically significant. The $F$ values of sheet thickness, corrugation height, and gasket pitch are 295.01, 54.34, and 20.54, respectively. The order affecting the average contact pressure is sheet thickness $(T)>$ corrugation height $(\mathrm{H})>$ gasket span $(\mathrm{P})$, consistent with range analysis. In the $F$ distribution boundary value table, $F_{0.05}(2,2)=19.00$, the corresponding $F$ value of the sheet thickness, gasket height, and corrugation pitch in the table were greater than $F_{0.05}(2,2)$. Therefore, it can be considered that these three factors have a significant influence on the average contact stress when the confidence level is $95 \%$. Figure 23 is a graph of the mean value of the 
TABLE 4: Influencing factors and levels of gasket contact stress.

\begin{tabular}{lccc}
\hline Level & $T$ (thickness) $(\mathrm{mm})$ & $H$ (height) $(\mathrm{mm})$ & $P(\mathrm{pitch})(\mathrm{mm})$ \\
\hline 1 & 0.3 & 2 & 2.5 \\
2 & 0.45 & 3 & 3.5 \\
3 & 0.6 & 4 & 4.5 \\
\hline
\end{tabular}

TABLE 5: Range analysis.

\begin{tabular}{|c|c|c|c|c|}
\hline & \multicolumn{3}{|c|}{ Factor } & \multirow{2}{*}{ Average contact pressure $(\mathrm{MPa})$} \\
\hline & $T$ (thickness) & $H$ (height) & $P($ span $)$ & \\
\hline 1 & 1 & 1 & 1 & 540.77 \\
\hline 2 & 1 & 2 & 2 & 542.55 \\
\hline 3 & 1 & 3 & 3 & 601.4 \\
\hline 4 & 2 & 1 & 3 & 702.77 \\
\hline 5 & 2 & 2 & 1 & 705.44 \\
\hline 6 & 2 & 3 & 2 & 963.18 \\
\hline 7 & 3 & 1 & 2 & 902.16 \\
\hline 8 & 3 & 2 & 3 & 1112.52 \\
\hline 9 & 3 & 3 & 1 & 1245.36 \\
\hline K1 & 561.57 & 715.23 & 872.15 & \\
\hline $\mathrm{K} 2$ & 790.46 & 786.83 & 830.22 & \\
\hline $\mathrm{K} 3$ & 1086.68 & 936.64 & 736.33 & \\
\hline Range & 175.03 & 73.804 & 45.27 & \\
\hline
\end{tabular}

TABLE 6: Analysis on variance results.

\begin{tabular}{lccccc}
\hline & ss & $\mathrm{d} f$ & $\mathrm{~ms}$ & $F$ & $P$ \\
\hline Thickness & 415872 & 2 & 207936.0 & 295.0191 & 0.003378 \\
Height & 76593.9 & 2 & 38297.0 & 54.3357 & 0.018072 \\
Span & 29022.1 & 2 & 14511.0 & 20.5882 & 0.046322 \\
Residual & 1409.6 & 2 & 572 & \\
\hline
\end{tabular}

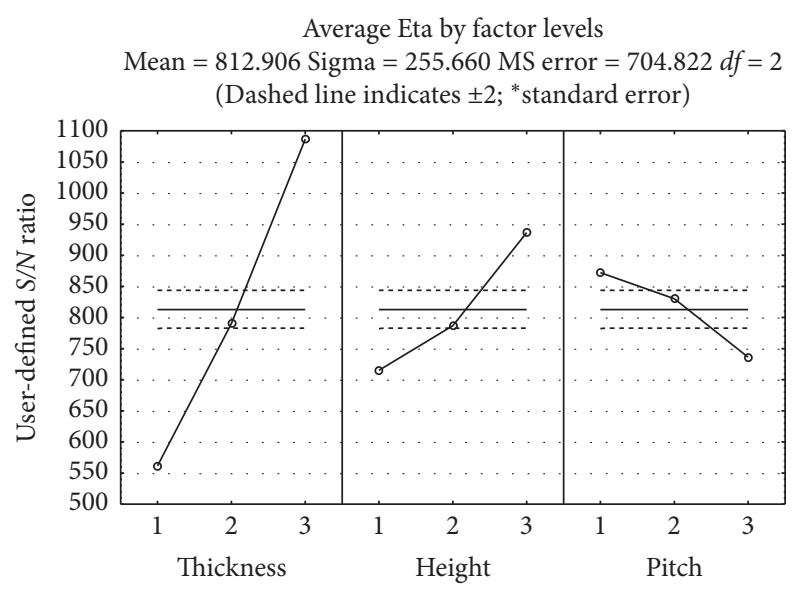

Figure 23: Mean plot of factors.

influencing factors of the contact pressure analysis of variance. It can be seen that the structural parameters of the SMA-CG were $T=0.6 \mathrm{~mm}, H=4 \mathrm{~mm}$, and $P=2.5 \mathrm{~mm}$, and the average contact stress of SMA-CG was the highest.

\section{Conclusions}

In this paper, the deformation mechanism of SMA gaskets was discussed according to its pseudoelastic and shape 
memory properties, and a constitutive SMA model under installation and operating conditions of bolted flange connections was established, which was verified by experiments, as well as its FEA method.

Based on this, the influence of SMA-CG structural parameters on its compression and springback mechanical properties under installation and operating conditions was examined. The results are as follows:

(1) Based on an SMA gasket thermal-mechanical coupling constitutive relationship model, an SMA corrugated structure thermal-mechanical coupling constitutive relationship model was established. Compared with the experimental results, the maximum error of the maximum compression load is $5.78 \%$, the maximum rebound rate is $8.85 \%$, and the error and the maximum error of the maximum compression force heat recovery stage change of $12.2 \%$ are less than $15 \%$, which is within the acceptable error range in the engineering field.

(2) Relevant experiments and finite element results of SMA corrugated specimens show that the maximum compression force of the gasket after unloading is not less than $40 \%$ of the initial maximum compression load. Therefore, the application of SMAs to corrugated gaskets is highly beneficial in improving their ability of handling load temperature fluctuations.

(3) The contact stress of SMA-CGs increased with increasing sheet thickness and corrugated gasket thickness under installation and operating conditions. Furthermore, a decreasing trend in contact stress was observed with increasing pitch. Under operating conditions, plate thickness had the greatest impact on average contact pressure, followed by gasket height and pitch. When SMA-CG structural parameters were $T=0.6 \mathrm{~mm}, H=4 \mathrm{~mm}$, and $P=2.5 \mathrm{~mm}$, the contact stress of the corrugated gasket was the highest.

There are two major limitations in this study that could be addressed in future research. First, according to the deformation mechanism of the corrugated gasket, the corrugated specimen was prepared and verified by related experiments. Further research on the preparation process of the SMA-CG and verification of the sealing performance of the optimized structure will help the engineering application of the SMA-CG. Secondly, the contact stress of corrugated gaskets of different sizes under a uniform temperature field is studied. The application of SMACG can be expanded by studying the contact stress of the corrugated gasket size in the nonuniform temperature field.

\section{Data Availability}

The data used to support the findings of this study are included within the article.

\section{Conflicts of Interest}

The authors declare that there are no conflicts of interest regarding the publication of this paper.

\section{Acknowledgments}

Financial supports from the National Natural Science Foundations of China (nos. 11772147 and 12027901), Major University Science Research Project of Jiangsu Province, China (no. 20KJA460001), and Natural Science Foundation of Jiangsu Province, China (no. BK20200706) were gratefully acknowledged.

\section{References}

[1] Y. Zhan, L. He, X. Lu, X. Zhu, and Q. Chen, "The effect of ageing treatment on shape-setting and shape memory effect of a NiTi SMA corrugated structure," Advances in Materials Science and Engineering, vol. 2020, Article ID 2846721, 11 pages, 2020.

[2] Z. Liu, "Metal corrugated gasket and its development," PetroChemical Equipment Technology, vol. 22, no. 5, pp. 39-41, 2001.

[3] T. Tatsuoka, Y. Takagi, and T. Sawa, "Analysis of bolted joints-sealing performance of pipe flange connections with shape memory alloy gaskets under internal pressure," in Proceedings of the ASME/JSME 2004 Pressure Vessels and Piping Conference, San Diego, CA, USA, July 2004.

[4] Y. Takagi, "Stress analysis and sealing performance of pipe flange connections with NiTi shape memory alloy gasket," in Proceedings of the ASME 2007 Pressure Vessels and Piping Conference, San Antonio, TX, USA, 2007.

[5] T. Sawa, Y. Takagi, and T. Tatsuoka, "Thermal stress analysis and evaluation of sealing performance in pipe flange connections with spiral wound gaskets under elevated temperature and internal pressure," in Proceedings of the ASME Pressure Vessels \& Piping Conference, Denver, CO, USA, 2005.

[6] X. Lu, G. Li, L. Liu, X. Zhu, and S.-T. Tu, "Effect of ambient temperature on compressibility and recovery of NiTi shape memory alloys as static seals," Advances in Mechanical Engineering, vol. 9, no. 2, 2017.

[7] X. Lu, G. Li, L. Liu, X. Zhu, and S.-T. Tu, "Effect of aging treatment on the compressibility and recovery of NiTi shape memory alloys as static seals," Journal of Materials Engineering and Performance, vol. 26, pp. 3025-3033, 2017.

[8] A. Bazergui and J. Winter, Room Temperature and Elevated Temperature Tests of a Metal Corrugated Gasket with Flexible Graphite Fill, Vol. 158, ASME, , New York, NY, USA, 1989.

[9] H. A. Saeed, S. Izumi, S. Sakai, S. Haruyama, M. Nagawa, and H. Noda, "Development of new metallic gasket and its optimum design for leakage performance," Journal of Solid Mechanics and Materials Engineering, vol. 2, no. 1, pp. 105$114,2008$.

[10] M. A. Choiron, S. Haruyama, and K. Kaminishi, "Optimization of new metal gasket design based on contact width involving contact stress consideration," Applied Mechanics \& Materials, vol. 110-116, pp. 4780-4787, 2012.

[11] M. A. Choiron, S. Haruyama, and K. Kaminishi, "Optimum design of new $25 \mathrm{~A}$-size metal gasket considering plastic contact stress," International Journal of Modeling and Optimization, vol. 1, no. 2, pp. 146-150, 2011.

[12] M. A. Choiron, S. Haruyama, and K. Kaminishi, "Studies of relationship between contact width and leakage on large size of new metal gasket," Applied Mechanics and Materials, vol. 229-231, pp. 705-709, 2012.

[13] H. Shigeyuki, D. Nurhadiyanto, K. Ushijima, K. Kaminishi, and D. H. Chen, "Deformation characteristic of thin stainless 
gasket material," Applied Mechanics and Materials, vol. 392, pp. 3-8, 2013.

[14] D. Nurhadiyanto, S. Mujiyono, and F. A. Ristadi, "Simulation analysis of $25 \mathrm{~A}$-size corrugated metal gasket coated copper to increase its performance," in Proceedings of the 2018 International Conference on Mechanical Engineering and Applied Composite Materials, Hong Kong, China, November 2018.

[15] S. Haruyama, M. A. Choiron, and D. Nurhadiyanto, "Optimum design of laminated corrugated metal gasket using computer simulation," International Journal of Integrated Engineering, vol. 11, no. 5, 2019.

[16] A. Efremov, "Bolted flanged connection for critical engineering applications," in Proceedings of the ASME 2006 Pressure Vessels and Piping/ICPVT-11 Conference, Vancouver, Canada, 2006.

[17] A. Efremov, "High temperature negative creep gasket and manufacturing same," US patent 2009/0134587, 2009.

[18] A. Efremov, "Negative creep corrugated gasket and methods of manufacturing same," US patent 2012/0286480, 2012.

[19] A. Efremov, "Negative creep gasket with core of shape memory alloy," US patent 2007/0241516, 2007.

[20] C. Liang and C. A. Rogers, "One-dimensional thermomechanical constitutive relations for shape memory materials," Journal of Intelligent Material Systems \& Structures, vol. 1, no. 2, pp. 207-234, 1990.

[21] M. Ben Jaber, H. Smaoui, and P. Terriault, "Finite element analysis of a shape memory alloy three-dimensional beam based on a finite strain description," Smart Materials \& Structures, vol. 17, no. 4, Article ID 045005, 2008.

[22] M. B. Jaber, M. A. Trojette, and F. Najar, "A finite element analysis of a new design of a biomimetic shape memory alloy artificial muscle," Smart Structures \& Systems, vol. 16, no. 3, pp. 479-496, 2014.

[23] X. Wang, B. Xu, and Z. Yue, "Phase transformation behavior of pseudoelastic NiTi shape memory alloys under large strain," Journal of Alloys and Compounds, vol. 463, no. 1-2, pp. 417-422, 2008.

[24] B. Kiefer, Modeling of Magnetic SMAs, Springer, Berlin, Germany, 2008. 